\title{
Cross-Border Banking Flows Spillovers in the Eurozone: Evidence from an Estimated DSGE Model
}

\author{
Jean-Christophe Poutineau* Gauthier Vermandel ${ }^{\dagger}$
}

This version: July 16, 2014

\begin{abstract}
This paper seeks to evaluate quantitatively how interbank and corporate crossborder flows shape business cycles in a monetary union. Using Bayesian techniques, we estimate a two-country DSGE model that distinguishes between Eurozone core and peripheral countries and accounts for national heterogeneities and a set of real, nominal and financial frictions. We find evidence of the key role of this cross-border channel as an amplifying mechanism in the diffusion of asymmetric shocks. Our model also reveals that under banking globalization, most national variables and the central bank interest rate are less sensitive to financial shocks while investment and current account imbalances are more sensitive to financial shocks. Finally, a counterfactual analysis shows that cross-border lending has affected the transmission of the recent financial crisis between the two groups of countries.
\end{abstract}

JEL classification: E32; E44; E52; F36; F41;

Keywords: Banking Globalization; Monetary Policy; Financial Accelerator; Interbank Market; Eurozone; Cross-border Lending

\footnotetext{
${ }^{*}$ CREM, UMR CNRS 6211, Université de Rennes I, Rennes, France. E-mail: jeanchristophe.poutineau@univ-rennes1.fr

${ }^{\dagger}$ CREM, UMR CNRS 6211, Université de Rennes I, Rennes, France. E-mail: gauthier@vermandel.fr

We are grateful to Miguel Casares and Dimitris Korobilis for helpful comments on Bayesian estimations. We benefited from discussions with Luca Fornaro, Robert Kollmann, Samuel Maveyraud, Dominik M. Rosch, Katheryn Russ and Marc-Alexandre Senegas as well as seminar participants at CEPR Workshop on the Economic of Cross-Border Banking, Association Francaise de Sciences Economiques (AFSE), Universidad Publica de Navarra, 30th International Symposium on Money, Banking and Finance (GDRE), Universite Rennes 1. The revised paper was written while Gauthier Vermandel was working for European Central Bank, DG-Macro-Prudential Policy and Financial Stability, MacroFinancial Linkages Division in 2014. We remain responsible for any errors and omissions
} 


\section{Introduction}

By eliminating currency risk, the adoption of the euro in 1999 generated forces for a greater economic and financial integration. The single currency reshaped financial markets and international investment patterns by enhancing cross-border banking activity between the members of the European Monetary Union (EMU). This phenomenon can be measured along various complementary dimensions such as the increase of FDI in bank activities, the diversification of bank assets and liabilities between countries, the access of local banks to international financial sources or through the increase of banks' lending via foreign branches and direct cross-border lending.

This paper focuses more specifically on the consequences of the rise in cross-border loan flows observed since the adoption of the Euro in 1999. Cross-border lending is a distinguishing feature of financial integration in the Eurozone: ${ }^{1}$ it has been multiplied by 3 in 9 years, before experiencing a $25 \%$ decrease after the recent financial crisis. The critical role of cross-border lending in the EMU must be assessed by taking into account the key role of banks in providing the main funding source for households and firms in the euro area: in 2012 the banking sector in the European Union was 4.5 times larger than its US counterpart (respectively $347 \%$ of EU GDP and $74 \%$ of US GDP). At its peak value in 2008, total cross-border lending represented around $120 \%$ of GDP for Eurozone countries, while the corresponding figure was $40 \%$ for the US and $20 \%$ for Japan. Taking a closer look at the data, this cross-border phenomenon is heterogenous as it affects mainly interbank lending and corporate lending, while cross-border lending to households is negligible ${ }^{2}$

We develop a two-country DSGE model to document how the transmission of asymmetric shocks in the Eurozone has been affected with a banking system that provides cross-border interbank and corporate lending facilities. This solution is original with respect to the existing literature of monetary policy issues in a monetary union. Indeed, most papers related to this topic can roughly be separated in two strands. On the one hand, one-country models such as Gerali et al. (2010), Pariès et al. (2011) and Christiano et al. (2010), assume complete banking integration so that all countries are impacted in the same way by the ECB monetary policy. On the other hand, two-country models such Kollmann et al. (2011) ignore the possibility of cross-border funds. In the meanwhile, the fewer models that adopt a middle of the road solution by assuming an imperfect integration of the loan market (Faia (2007); Dedola and Lombardo (2012); Ueda (2012); Dedola et al. (2013)) do not account for the above mentioned heterogeneity

\footnotetext{
${ }^{1}$ See Fig. 1 in the text below.

${ }^{2}$ As underlined by Fig. 2, European banks mainly finance foreign banks on the interbank market and foreign firms on the corporate credit market while mortgage and deposit markets remain strongly segmented in the Eurosystem.
} 
in Eurozone cross-border loan flows.

Our paper brings theoretical and empirical contributions. To keep the model tractable, we analyze cross-border loans through home bias in the borrowing decisions concerning interbank and corporate loans using CES function aggregates ${ }^{3}$. Cross-border banking flows are introduced analogously to standard trade channel assuming CES function aggregates. This modelling strategy is flexible as it allows to treat in a more compact way two levels of cross-border lending related to interbank loans and corporate loans. The heterogeneity between national financial systems is accounted for through different interest rate set by financial intermediaries. In our setting, bonds are mainly used, as in the intertemporal macroeconomics literature, to allow households to smooth intertemporally consumption and countries to finance current account deficits. Thus, our model does not truly introduce banking but rather reinterpret the financial accelerator from a banking perspective ${ }^{4}$.

To enhance the empirical relevance of the model we introduce a set of nominal, financial and real rigidities. We estimate the model on quarterly data using Bayesian techniques over a sample time period running from 1999Q1 to 2013Q3. The estimation procedure is implemented by splitting the Eurozone in two groups of countries, the core and the periphery. According to our estimates, we find that accounting for cross-border loans strongly improves the fit of the model.

In this setting, we find evidence of the role of cross-border lending channel as an amplifying mechanism for the transmission of asymmetric shocks. First, using Bayesian impulse response functions, we get two main results. In all cases, cross-border lending leads to more diverging investment cycles following either real or financial shocks and, as a consequence, clearly affects the dynamics of the current account with respect to the segmentation of the loan market. Furthermore, cross-border loans amplify the transmission of a negative financial shock on aggregate activity in the Eurozone. Second, an analysis of the historical variance decomposition shows that for most variables cross-border lending has reduced the impact of national financial shocks on national variables while it has increased the effect of financial shocks on the bilateral current

\footnotetext{
${ }^{3}$ Home bias in the borrowing decisions catches up some extra costs involved by cross-border activities, such as increasing monitoring costs due to the distance, differences in legal systems and payments, etc. These iceberg costs are closely related to home biais as underlined by Obstfeld and Rogoff (2001).

${ }^{4}$ As a first modelling choice, we do not attempt to model explicitly the balance sheet of the banking system but we try to capture the key elements relevant to our analysis, namely the way the accelerator is affected by cross-border lending. We thus depart from some recent papers where the balance sheet of the banking system lies at the heart of the analysis such as Angeloni and Faia (2013) (that provide an integrated framework to investigate how bank regulation and monetary policy interact when the banking system is fragile and may be subject to runs depending on their degree of leverage) or Gertler and Karadi (2012) (where financial intermediaries face endogenously determined balance sheet constraints to evaluate the effects of unconventional monetary policy decisions to dampen the effect of the financial crisis).
} 
account between core and peripheral countries. Third, we perform a counterfactual exercise to evaluate the effect of cross-border banking in the transmission of the financial crisis between the two groups of countries. We find that peripheral countries have been much more affected by the crisis through a deeper impact on interbank loan shortage and that the degree of cross-border banking affects the time path of the main national macroeconomic indicators.

The rest of the paper is organized as follows: Section 2 presents some stylized facts and a quick summary of the related literature. Section 3 describes the financial component of model. Section 4 presents the real component of the model. Section 5 presents the data and the econometric method. Section 6 uses Bayesian IRFs to evaluate the consequences of cross-border bank lending on the transmission of asymmetric real and financial shocks. Section 7 provides a quantitative evaluation of the consequences of cross-border flows on the volatility of representative aggregates. Section 8 concludes.

\section{Stylized Facts and Related Literature}

\subsection{Cross-border lending in the Eurozone}

Cross-border lending is a distinguishing feature of financial integration in the Eurozone. As reported in panel (a) of Fig. 1, between 1999Q1-2012Q1, cross-border loans have increased much more between participating counties than between the Eurozone and the European Union, and even much more than with countries outside Europe. The rise in cross-border loans is peaking in 2008, where cross-border loans represented $300 \%$ of the value initially observed in 1999. The financial crisis is characterized by a $25 \%$ drop in cross-border lending between Euro partners. As underlined in panel (b), in 2008, cross-border lending represented around 120\% of GDP for Eurozone countries at its peak value, while the corresponding figures were $40 \%$ for the US and $20 \%$ for Japan. However, a closer view at the data underlines the heterogeneity of bilateral flows within the Eurozone. In Fig. 2, we split the Eurozone in two groups: core countries and peripheral countries. In the first group we aggregate data for Germany and France, while in the second group, we aggregate data for Spain, Greece, Ireland, Italy and Portugal. We summarize the main stylized fact by contrasting interbank loans (in panel (a)), Corporate loans (in panel (b)) and loans to households (in panel (c)). Cross border loans are reported as the percentage of loans exported to the other economies either by core countries (plain lines) or peripheral countries (dotted lines). Thus, each curve represents the percentage points of loans exported by the relevant group of countries towards the rest of the Monetary Union. 


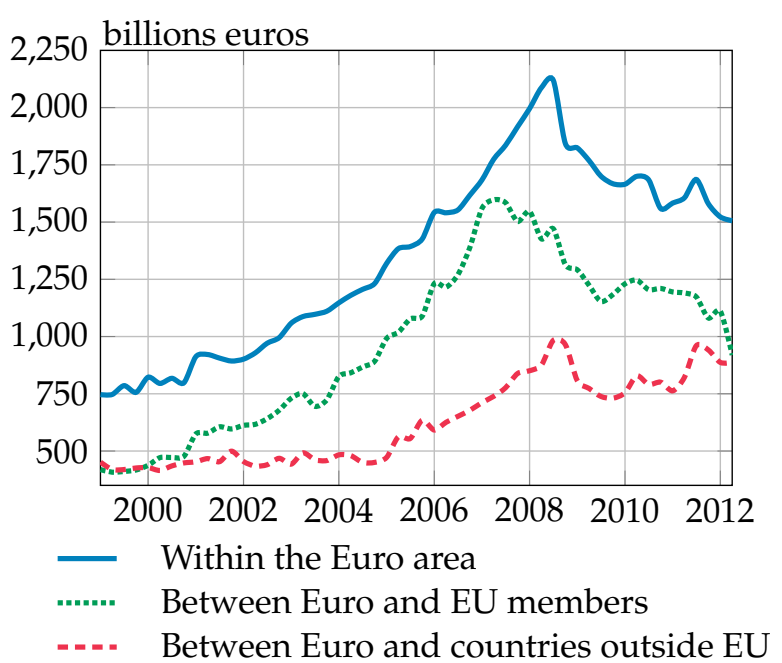

(a) Cross-border loans of MFIs residing in the euro area

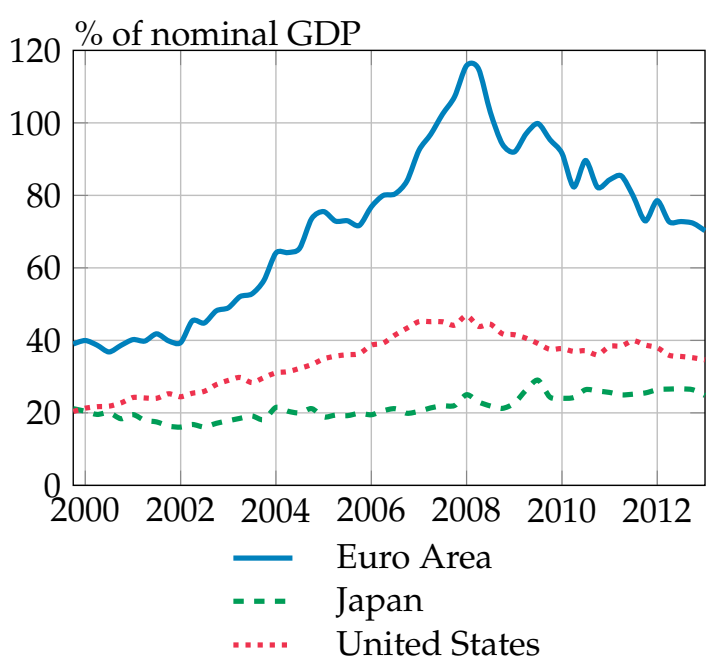

(b) Total Amount of Banks' Foreign Claims in \% of nominal GDP

Figure 1: Internationalization of credit markets in the Eurozone and abroad between 1999 and 2013 (Sources ECB, BIS)

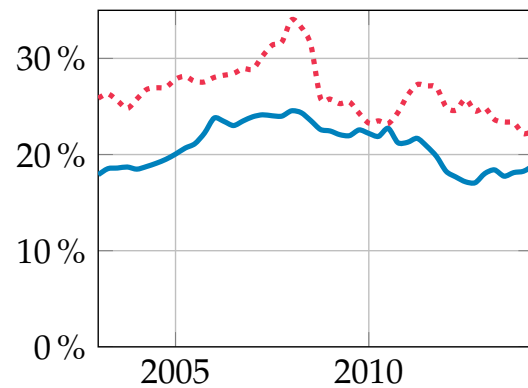

(a) Interbank Loans

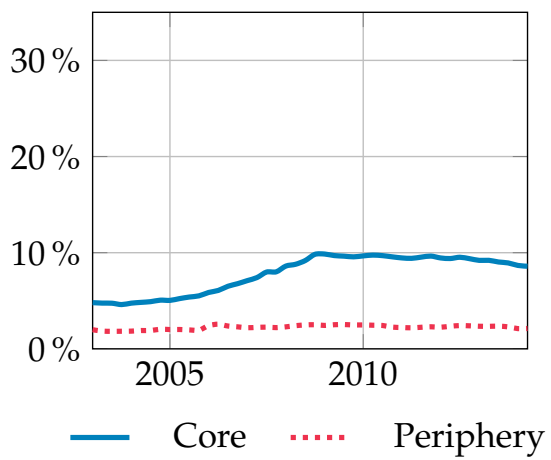

(b) Corporate Loans

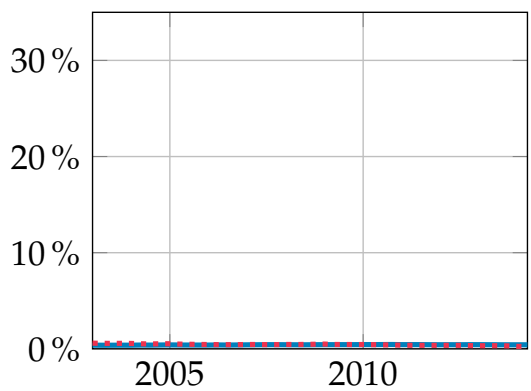

(c) Loans to Households

Figure 2: Share of Cross-Border Loans between EMU participants in the assets of Core and Peripheral Banks

The picture clearly shows the main contribution of interbank loans to cross border lending in the Eurozone, as they represent $25 \%$ on average over the sample period for peripheral countries and $20 \%$ for core countries. The financial crisis of 2008 had a clear depressing impact on cross-border lending from peripheral countries while it left crossborder lending from core countries almost unchanged. Peripheral countries cross-border lending to firms is low and remains constant over the sample period (averaging $2 \%$ of total loan creation) while it has clearly increased for core countries before the propagation of the financial crisis in the Eurozone (from 5\% of total national loans in 2003 to $10 \%$ in 2008). The financial crisis has affected cross-border lending by stabilizing its level at around $10 \%$ over these last years for core countries, while having no noticeable effect for peripheral countries. Finally, cross-border lending to households is almost negligible 
over the sample period: it represents a constant value of $0.4 \%$ of total household loans for core countries and almost the same value on average (with a monotone downward trend) for peripheral countries.

\subsection{A quick summary of the related literature}

Recently a few authors have proposed DSGE models with cross-border lending features to assess the relevance of financial factors in the international transmission of shocks. Moreover, these models fall in one of the three following categories: international financial accelerators (Dedola and Lombardo (2012) and Ueda (2012)), Global banks (Kollmann et al. (2011) and Kalemli-Ozcan et al. (2013)) and international borrowing constraint (Faia and Iliopulos (2011) and Guerrieri et al. (2012)). However, none of these papers analyses the heterogeneity in cross-border lending flows combining corporate and interbank loans.

Concerning the first category of models of international credit cycles, Dedola and Lombardo (2012) suggest that cross-border spillovers result from holding foreign assets by domestic agents. In their model, entrepreneurs solve an endogenous portfolio choice problem composed by home and foreign assets. A variation of asset prices in one economy has side effects on the other economy, as investors sell or buy both domestic and foreign assets. Analytically, this model has to be solved using a second-order approximation to the policy function. ${ }^{5}$ In the same vein, Ueda (2012) extends the financial accelerator in a two-country framework and imposes a credit constraint for both entrepreneurs and banks using a financial accelerator mechanism. Under banking globalization, the cost of capital in the economy depends on the capital to net wealth ratio of home and foreign entrepreneur and banks. The model of Ueda is close to Dedola and Lombardo, as entrepreneurs and banks maximize profits that combine an average of home and foreign funds calibrated in steady state.

Turning to the second category, both Kollmann et al. (2011) and Kalemli-Ozcan et al. (2013) consider a two-country environment with a global banking sector. When the capitalization of global banks declines, it reduces credit supply and depresses economic activity in both countries. In their setting financial frictions are reinforced by the fact that bank losses raise intermediation costs in both countries, triggering synchronized business fluctuations. However, these models consider an homogeneous banking system in the Eurozone while we introduce asymmetries in lending rate settings and financial

\footnotetext{
${ }^{5}$ Bringing the model to the data is very challenging as if the estimated variance of the shocks are too big (which is mainly the case with financial data), the IRFs may diverge with a second order approximation. The solution we adopt in this paper does not need a second order approximation contrary to their framework.
} 
shocks between the core and the periphery to account for financial heterogeneity in the Eurozone.

Faia and Iliopulos (2011) develop a small open economy DSGE model with durable and non durable goods sectors where households face a collateral constraint on the foreign level of debt. The model offers a reduced form of the banking system and concentrates on housing that is financed through foreign lending. We do not use this model for our purposes given the marginal flows of cross-border loans for house purchases encountered in Eurozone data as showed in Fig. 2. Furthermore, as a small open country model, it can not be kept for our analysis that requires a two-country model. Finally, in the model developed by Guerrieri et al. (2012), banks grant loans to firms and invest in bonds issued by home and foreign government. The model is calibrated on the Euro area. In a two-country set-up, there are core and peripheral countries where large contractionary shocks trigger sovereign default. This model is well suited to analyze the diffusion of sovereign default risk in the Eurozone as shock to the value of peripheral bonds have side effects on the core economy. The model is also very rich in terms of financial frictions. However, the model is aimed at evaluating the diffusion of a sovereign debt crisis, a topic not covered in this paper.

One of the novelty of our analysis is to provide a simple way to model cross-border lending activity to account for the previous stylized facts. To take our two-country model to the data easily, we assume that the banking system determines the loan interest rate while the quantity of loans that is contracted is determined by loan demand. Thus, in this paper, rather than assuming that loans result of optimal portfolio choices from the supply side of the credit market, we suppose that the cross-border decisions arise from the demand side of credit market. International financial linkages are analogous to the external trade channels, assuming that a CES function aggregates domestic and international lending. This choice - that borrows from the New Open Economy Macroeconomics (NOEM) - remains quite simplistic but offers an interesting feature when going to the empirical estimation of the model and a simple reinterpretation of the financial accelerator from a banking perspective.

\section{A Monetary Union with Cross-border Loans}

We describe a two-country world. The two countries are equal in size and share a common currency. Each country $i \in\{h, f\}$ (where $h$ is for home and $f$ for foreign) is populated by consumers, labor unions, intermediate and final producers, entrepreneurs, capital suppliers and a banking system. Regarding the conduct of macroeconomic policy, we assume national fiscal authorities and a common central bank. As in Christiano 
et al. (2005) and Smets and Wouters (2003, 2007), we account for several sources of rigidities to enhance the empirical relevance of the model. The set of real rigidities encompasses consumption habits, investment adjustment costs, loan demand habits. Regarding nominal rigidities, we account for stickiness in final goods prices, wages and loan interest rates.

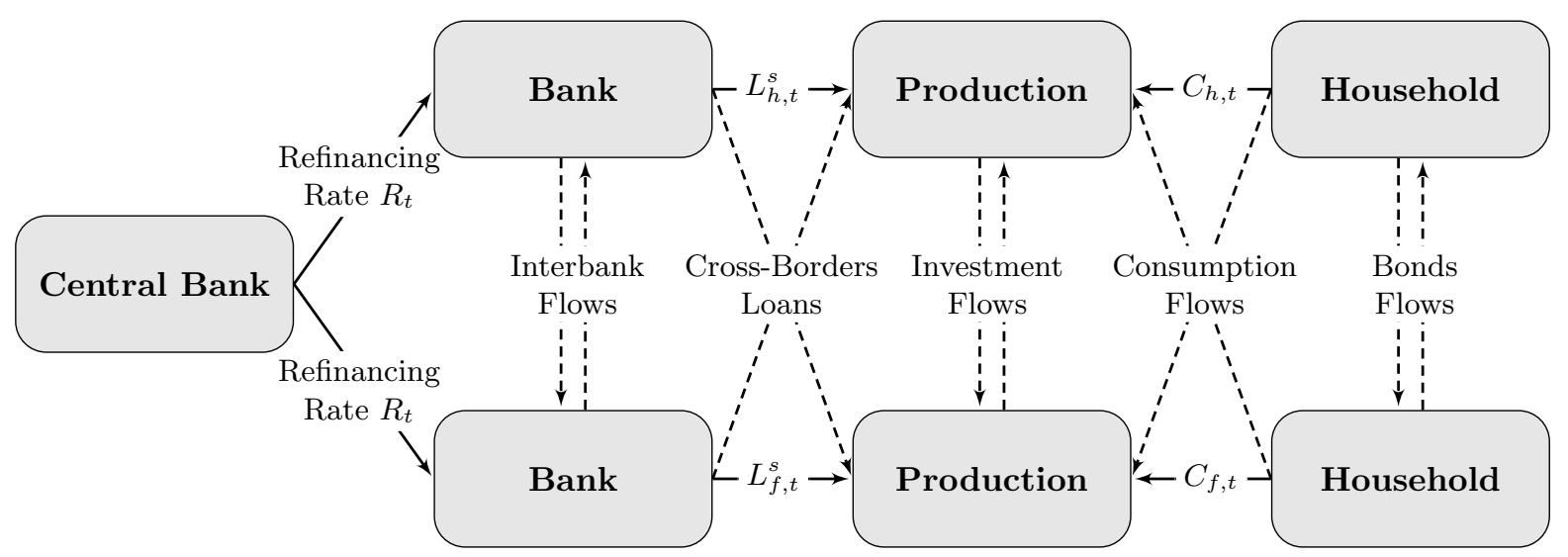

Figure 3: The model of a two-country monetary union with international bank loan flows

The general structure of the model is summarized in Fig. 3. For expository purposes, this section describes the financial component of the model. We first outline the structure of the banking system that gives rise to cross-border interbank loan, then we describe the origin of cross-border corporate loans. The standard new Keynesian and $\mathrm{RBC}$ components of the model are presented afterward in Section 4.

\subsection{An Heterogenous Banking System}

In each country, the banking sector finances investment projects to home and foreign entrepreneurs by supplying one period loans. The banking system is heterogenous with regard to liquidity, and banks engage in interbank lending at the national and international levels. Thus, cross-border loans are made of corporate loans (between banks and entrepreneurs) and interbank loans.

To introduce an interbank market, we suppose that the banking system combines liquid and illiquid banks. Normalizing the total number of banks in each economy to 1 , we assume that banks distributed over $[0, \lambda]$ are illiquid (i.e. credit constrained), while the remaining banks distributed over share $[\lambda, 1]$ are liquid and supply loans to entrepreneurs and to illiquid banks. We assume that a liquid bank is characterized by her direct accessibility to the ECB fundings. Conversely, an illiquid bank does not have access to the ECB fundings. This assumption is empirically motivated: in the Eurosystem, only a fraction of the 2500 banks participates regularly to the bidding process in 
main refinancing operations of the ECB while the others rely on interbank funding, as underlined by Gray et al. (2008). Extending this assumption in an international perspective, illiquid banks can borrow from both domestic and foreign liquid banks, which gives rise to cross-border interbank lending flows.

Illiquid Banks: The representative illiquid bank $b \in[0, \lambda]$ in country $i$ operates under monopolistic competition to provide a quantity of loans $L_{i, t+1}^{s}(b)$ to entrepreneurs that is financed by interbank loans $I B_{i, t+1}(b)$ from the interbank market (with a one period maturity) at a rate $P_{i, t}^{I B}$. The balance sheet of the bank writes,

$$
L_{i, t+1}^{s}(b)=I B_{i, t+1}^{\mathcal{H}}(b)+B K_{i, t+1}(b)+l i a b_{i, t},
$$

where $L_{i, t+1}^{s}(b)$ is the loan supply of borrowing banks, $I B_{i, t+1}^{\mathcal{H}}(b)$ is the interbank loans supplied by liquid banks subject to external habits, $B K_{i, t+1}(b)$ is the bank capital and $l i a b_{i, t}$ are other liabilities in the balance sheet of the bank that are not considered in the model ${ }^{6}$. We suppose that the demand for interbank funds are subject to external habits at a degree $h_{i}^{i b}$ where, $I B_{i, t+1}^{\mathcal{H}}(b)=I B_{i, t+1}^{d}(b)-h_{i}^{i b}\left(I B_{i, t+1}^{d}-\overline{I B_{i}^{d}}\right)$. These habits are deemed necessary to catch up the high autocorrelation observed in the supply of loans ${ }^{7}$.

This bank engages in corporate loans. In this setting, we assume that there is no discrimination between borrowers, so that the representative and risk-neutral bank serves both domestic and foreign entrepreneurs without taking into account specificities regarding the national viability of projects. Bank default expectation regarding entrepreneurs' projects is defined as, $\eta_{i, t+1} \equiv\left(1-\alpha_{i}^{L}\right) \eta_{h, t+1}^{E}+\alpha_{i}^{L} \eta_{f, t+1}^{E}$, where $\eta_{i, t+1}^{E}$ is the default rate in country $i \in\{h, f\}$ of entrepreneurs and $\left(1-\alpha_{i}^{L}\right)$ measures the home bias in corporate loan distribution. Thus, the marginal cost of one unit of corporate loan $M C_{i, t}^{i l l}(b)$ provided by the illiquid bank is the solution of the expected profit $\mathbb{E}_{t} \Pi_{i, t+1}^{B}(b)$ optimization problem,

$$
\max _{L_{i, t+1}^{s}(b)} \mathbb{E}_{t} \eta_{i, t+1} M C_{i, t}^{i l l}(b) L_{i, t+1}^{s}(b)-P_{i, t}^{I B}\left(L_{i, t+1}^{s}(b)-B K_{i, t+1}(b)-l i a b_{t}(b)\right)
$$

The marginal cost of one unit of loan, denoted $M C_{i, t}^{i l l}(b)$, is the same across illiquid banks,

$$
M C_{i, t}^{i l l}(b)=M C_{i, t}^{i l l}=\frac{P_{i, t}^{I B}}{\mathbb{E}_{t} \eta_{i, t+1}},
$$

\footnotetext{
${ }^{6}$ We suppose that they follow an exogenous $A R(1)$ shock process $\varepsilon_{i, t}^{B}$ such that, liab $_{i, t}=e^{\varepsilon_{i, t}^{B}} \overline{l i a b}_{i}$, this shock captures some aggregate movements in the capital constraint of banks.

${ }^{7}$ In the fit exercise, DSGE models with banking are estimated on the outstanding amount of loans contracted in the economy. Since DSGE models only include one-period maturity loans, external habits are a tractable way to catch up the high persistence in the loan contracts without modifying the steady state. Guerrieri et al. (2012) develops a similar financial friction in the borrowing constraint of entrepreneurs.
} 
so that each bank decides the size of the spread depending on the expected failure rate of its customers $\mathbb{E}_{t} \eta_{i, t+1}$. The bank has access to domestic and foreign interbank loans to meet its balance sheet. The total amount borrowed by the representative bank writes,

$$
I B_{i, t+1}^{d}(b)=\left(\left(1-\alpha_{i}^{I B}\right)^{1 / \xi} I B_{h, i, t+1}^{d}(b)^{(\xi-1) / \xi}+\left(\alpha_{i}^{I B}\right)^{1 / \xi} I B_{f, i, t+1}^{d}(b)^{(\xi-1) / \xi}\right)^{\xi /(\xi-1)}
$$

where parameter $\xi$ is the elasticity of substitution between domestic and foreign interbank funds, $\alpha_{i}^{I B}$ represents the percentage of cross-border interbank loan flows in the monetary union and $I B_{h, i, t+1}^{d}(b)$ (resp. $\left.I B_{f, i, t+1}^{d}(b)\right)$ the amount of domestic (resp. foreign) loans demanded by borrowing bank $b$ in country $i$. The total cost incurred by illiquid banks to finance interbank loans, $P_{i, t}^{I B}$, is thus defined according to the CES aggregator,

$$
P_{i, t}^{I B}=\left(\left(1-\alpha_{i}^{I B}\right)\left(R_{h, t}^{I B}\right)^{1-\xi}+\alpha_{i}^{I B}\left(R_{f, t}^{I B}\right)^{1-\xi}\right)^{1 /(1-\xi)},
$$

where $R_{h, t}^{I B}$ (resp. $R_{f, t}^{I B}$ ) is the cost of loans obtained from home (resp. foreign) banks in country $i$. The decision to borrow from a particular bank is undertaken on the basis of relative interbank national interest rates,

$I B_{h, i, t+1}^{d}(b)=\left(1-\alpha_{i}^{I B}\right)\left[\frac{R_{h, t}^{I B}}{P_{i, t}^{I B}}\right]^{-\xi} I B_{i, t+1}^{d}(b)$, and $I B_{f, i, t+1}^{d}(b)=\alpha_{i}^{I B}\left[\frac{R_{f, t}^{I B}}{P_{i, t}^{I B}}\right]^{-\xi} I B_{i, t+1}^{d}(b)$.

Here, cross-border lending is measured through the values undertaken by $I B_{h, f, t+1}^{d}(b)$, (i.e., interbank loans contracted by liquid foreign banks from domestic overliquid banks) and symmetrically by $I B_{f, h, t+1}^{d}(b)$ (i.e., interbank loans contracted by liquid domestic banks from foreign overliquid banks). Finally following Hirakata et al. (2009), the bank capital accumulation process of illiquid banks $\left(B K_{i, t+1}(b)\right)$ is determined by,

$$
B K_{i, t+1}(b)=\left(1-\tau^{B K}\right) \Pi_{i, t}^{B}(b),
$$

where $\tau^{B K}$ is a proportional tax on the profits of the bank.

Liquid Banks: The representative liquid bank $b \in[\lambda ; 1]$ in country $i$ operates under monopolistic competition to provide a quantity of loans $L_{i, t+1}^{s}(b)$ to entrepreneurs. It also provides a quantity of interbank loans $I B_{i, t+1}^{s}(b)$ to illiquid banks. We suppose that the intermediation process between liquid and illiquid banks is costly: we introduce a convex monitoring technology à la Cúrdia and Woodford (2010) and Dib (2010) with a functional form $A C_{i, t+1}^{I B}(b)=\frac{\chi_{i}^{I B}}{2}\left(I B_{i, t+1}^{s}(b)-\overline{I B}_{i}^{s}(b)\right)^{2}$ where parameter $\chi_{i}^{I B}$ is the level of financial frictions between liquid banks in country $i$ and home and foreign illiquid banks $^{8}$. Loans created by the liquid bank are financed by one-period maturity loans

\footnotetext{
${ }^{8}$ Contrary to Cúrdia and Woodford (2010) but in the same vein of Dib (2010), the monitoring technology does not alter the steady state of the model to keep the estimation of $\chi_{i}^{I B}$ as simple as
} 
from the central bank $\left(L_{i, t+1}^{E C B}(b)\right)$ at the refinancing interest rate $R_{t}$. Finally, the bank's balance sheet is defined by,

$$
L_{i, t+1}^{s}(b)+I B_{i, t+1}^{s}(b)=L_{i, t+1}^{E C B}(b)+B K_{i, t+1}(b)+l i a b_{t}(b) .
$$

According to the behavior of illiquid banks, we assume that there is no discrimination between borrowers. The marginal cost of one unit of loan $M C_{i, t}^{l i q}(b)$ solves the profit $\left(\Pi_{i, t}^{B}(b)\right)$ maximization problem,

$\max _{L_{i, t+1}^{s}(b), I B_{i, t+1}(b)} \mathbb{E}_{t} \eta_{i, t+1} M C_{i, t}^{l i q}(b) L_{i, t+1}^{s}(b)+R_{i, t}^{I B}(b) I B_{i, t+1}^{s}(b)-R_{t} L_{i, t+1}^{E C B}(b)-A C_{i, t+1}^{I B}(b)$.

The marginal cost of one unit of loan is the same for all liquid banks,

$$
M C_{i, t}^{l i q}(b)=M C_{i, t}^{l i q}=\frac{R_{t}}{\mathbb{E}_{t} \eta_{i, t+1}}
$$

Similarly to the illiquid bank, bank capital evolves according to Eq. (6) ${ }^{9}$.

Loan interest rates: There are two interest rates to be determined: the interest rate on the interbank market and the interest rate on corporate loans. First, on a perfectly competitive market, the interbank rate in country $i$ is determined from the problem (7),

$$
R_{i, t}^{I B}(b)=\chi_{i}^{I B}\left(I B_{i, t+1}(b)-\overline{I B}_{i}^{s}(b)\right)+R_{t}
$$

where, $\chi_{i}^{I B}$ is a cost parameter, $I B_{i, t+1}^{s}(b)$ is the amount of interbank loans contracted in period $t$ with a one period maturity and $\overline{I B}_{i}^{s}(b)$ is the steady state value of interbank loans.

Second, the interest rate charged by banks of country $i$ on corporate loans accounts for the liquidity of the national banking system. Anticipating over symmetric issues at the equilibrium to improve the tractability of the model, we assume that all banks belonging to a national banking system share the same marginal cost of production, reflecting the average liquidity degree of national banks. Thus, aggregating over each group of banks, we get, $\int_{0}^{\lambda} M C_{i, t}^{i l l}(b) \mathrm{d} b=M C_{i, t}^{L, i l l}$, and $\int_{\lambda}^{1} M C_{i, t}^{l i q}(b) \mathrm{d} b=M C_{i, t}^{l i q}$. Aggregate marginal cost $M C_{i, t}^{L}$ combines outputs from liquid and illiquid banks of country $i$

possible. Several papers refer to monitoring technology functions in the intermediation process of banks, see for example Goodfriend and McCallum (2007) or Casares and Poutineau (2011).

${ }^{9}$ The accumulation of bank capital is necessary to close the model but it is not binding for liquid banks as they are not credit constrained. 
according to ${ }^{10}$

$$
M C_{i, t}^{L}=\left(M C_{i, t}^{i l l}\right)^{\lambda}\left(M C_{i, t}^{l i q}\right)^{(1-\lambda)}=\frac{\left(P_{i, t}^{I B}\right)^{\lambda}\left(R_{t}\right)^{(1-\lambda)}}{\mathbb{E}_{t} \eta_{i, t+1}}
$$

Thus, the representative bank $b \in[0 ; 1]$ of country $i$ operates under monopolistic competition to provide a quantity of loans $L_{i, t+1}^{s}(b)$ incurring a marginal cost $M C_{i, t}^{L}$. The marginal cost is the same for all banks $b$ and depends on the expected failure rate of borrowers' projects and the central bank refinancing rate. Eq. (10) taken in logs becomes,

$$
\widehat{m c}_{i, t}^{L}=\frac{1}{(1-\bar{N} / \bar{K})}\left[\left(1-\alpha_{i}^{L}\right)\left(1-\varkappa_{i}\right) \widehat{l e v}_{i, t}+\alpha_{i}^{L}\left(1-\varkappa_{j}\right) \widehat{l e v}_{j, t}\right]+(1-\lambda) \hat{r}_{t}+\lambda \hat{p}_{i, t}^{I B},
$$

$\forall i \neq j \in\{h, f\}$, where, $\widehat{\operatorname{lev}}_{i, t}$ is the leverage ratio of entrepreneurs and $\bar{N} / \bar{K}$ is the steady state net worth to capital ratio. Under Calvo pricing with partial indexation, banks set the interest rate on loans contracted by entrepreneurs on a staggered basis as in Pariès et al. (2011). A fraction $\theta_{i}^{L}$ of banks is not allowed to optimally set the credit rate ${ }^{11}$ and index it by $\xi_{i}^{L}$ percent of the past credit rate growth, $R_{i, t}^{L}(b)=\left(R_{i, t-1}^{L} / R_{i, t-2}^{L}\right)^{\xi_{i}^{L}} R_{i, t-1}^{L}(b)$. Assuming that it is able to modify its loan interest rate with a constant probability $1-\theta_{i}^{L}$, it chooses $R_{i, t}^{L *}(b)$ to maximize its expected sum of profits,

$$
\max _{\left\{R_{i, t}^{L *}(b)\right\}} \mathbb{E}_{t}\left\{\sum_{\tau=0}^{\infty}\left(\theta_{i}^{L} \beta\right)^{\tau} \frac{\lambda_{i, t+\tau}^{c}}{\lambda_{i, t}^{c}} \eta_{i, t+1+\tau}\left[\left(1-\tau^{L}\right) R_{i, t}^{L *}(b) \Xi_{i, t, \tau}^{L}-M C_{i, t+\tau}^{L}\right] L_{i, t+1+\tau}(b)\right\}
$$

subject to, $L_{i, t+1+\tau}(b)=\left(\Xi_{i, t, \tau}^{L} R_{i, t}^{L *}(b) / R_{i, t+\tau}^{L}\right)^{-\mu_{i, t+\tau}^{L} /\left(\mu_{i, t+\tau}^{L}-1\right)} L_{i, t+1+\tau}, \forall \tau>0$, where $\Xi_{i, t, \tau}^{L}=\prod_{k=1}^{\tau}\left(R_{i, t+k-1}^{L} / R_{i, t+k-2}^{L}\right)^{\xi_{i}^{L}}$ is the sum of past credit rate growth and $L_{i, t}(b)$ denotes the quantity of differentiated banking loans $b$ that is used by the retail banks ${ }^{12}$. The time-varying markup is defined by, $\mu_{i, t}^{L}=\mu_{L}+\varepsilon_{i, t}^{L}$, so that an increase in $\varepsilon_{i, t}^{L}$ can be interpreted as a cost-push shock to the credit rate equation ${ }^{13}$. As Benigno and Woodford (2005), we introduce a proportional $\operatorname{tax} \tau^{L}$ on profits that restores the firstbest allocation in the steady state. Allowing for a partial indexation of credit interest rates on their previous levels (where $\xi_{i}^{L} \in[0 ; 1]$ is the level of indexation that catches some imperfect interest rate pass-though with $\theta_{i}^{L}$ ), and imposing symmetry, the log

\footnotetext{
${ }^{10}$ We borrow this aggregation procedure from the solution introduced by Gerali et al. (2010), to aggregate borrowing and saving households labor supply.

${ }^{11}$ This parameter, once estimated in the next section, will serve as a measure to measure the flexibility of national banking systems in the transmission of interest rate decisions.

${ }^{12}$ Retail banks are perfectly competitive loan packers, they buy the differentiated loans and aggregate them through a CES technology into one loan and sell them to entrepreneurs.

${ }^{13}$ Differentiated loans are imperfect substitutes, with elasticitity of substitution denoted by $\frac{\mu_{L}}{\left(\mu_{L}-1\right)}$.
} 
equation of the real loan interest rate in country $i$ is set according to,

$$
\hat{r}_{i, t}^{L}=\frac{1}{1+\beta\left(1+\xi_{i}^{L}\right)}\left(\begin{array}{c}
\left(1+\xi_{i}^{L}(1+\beta)\right) \hat{r}_{i, t-1}^{L}-\xi_{i}^{L} \hat{r}_{i, t-2}^{L}+\beta \mathbb{E}_{t} \hat{r}_{i, t+1}^{L} \\
+\beta \theta_{i}^{L} \mathbb{E}_{t} \hat{\pi}_{i, t+2}^{c}-\left(1+\beta \theta_{i}^{L}\right) \mathbb{E}_{t} \hat{\pi}_{i, t+1}^{c}+\hat{\pi}_{i, t}^{c} \\
+\frac{\left(1-\theta_{i}^{L}\right)\left(1-\theta_{i}^{L} \beta\right)}{\theta_{i}^{b}}\left[\widehat{m c}_{i, t}^{L}-\hat{r}_{i, t}^{L}\right]
\end{array}\right)+\varepsilon_{i, t}^{L} .
$$

Solving this equation forward, one can see that past, current and expected future marginal cost of loans are driving today's loan interest rate. With fully flexible rates $\left(\theta_{i}^{L}=0\right)$, the loan interest rate $\hat{r}_{i, t}^{L}$ is a function of the interest rate and the expected profitability share of investment projects, that is $\hat{r}_{i, t}^{L}=\widehat{m c}_{i, t}^{L}+\varepsilon_{i, t}^{L}=\hat{r}_{t}-E_{t} \widehat{\eta}_{i, t+1}+\varepsilon_{i, t}^{L}$. Since credit risk is measured by the level of firm leverage in the economy, credit rates reflect both past and future risk in the economy caught up by parameters $\xi_{i}^{L}$ and $\theta_{i}^{L}$.

\subsection{Entrepreneurs and Corporate loans}

Cross-border corporate loans occur between entrepreneurs and banks. In each economy, the representative entrepreneur $e \in[0,1]$ finances the capital renting of intermediate firms. In period $t$, entrepreneur $e$ conducts a great number of heterogenous projects with total value $Q_{i, t} K_{i, t+1}(e)$, (where $Q_{i, t}$ is the price of capital and $K_{i, t+1}(e)$ is the amount of capital financed). These projects are financed by his net wealth and by loans from the banking system $\left(L_{i, t+1}^{d}(e)\right)$. The balance sheet of the representative entrepreneur writes,

$$
Q_{i, t} K_{i, t+1}(e)-N_{i, t+1}(e)=L_{i, t+1}^{\mathcal{H}}(e) .
$$

where $L_{i, t+1}^{\mathcal{H}}(e)=L_{i, t+1}^{d}(e)-h_{i}^{L}\left(L_{i, t}^{d}-L_{i}^{d}\right)$ denotes external demand habits for loans ${ }^{14}$. The entrepreneur has access to domestic and foreign banks to meet its balance sheet. The total amount borrowed by the representative entrepreneur writes,

$$
L_{i, t+1}^{d}(e)=\left(\left(1-\alpha_{i}^{L}\right)^{1 / \nu} L_{h, i, t+1}^{d}(e)^{(\nu-1) / \nu}+\left(\alpha_{i}^{L}\right)^{1 / \nu} L_{f, i, t+1}^{d}(e)^{(\nu-1) / \nu}\right)^{\nu /(\nu-1)}
$$

where parameter $\nu$ is the elasticity of substitution between domestic and foreign loans, $\alpha_{i}^{L}$ represents the percentage of cross-border loan flows in the monetary union and $L_{h, i, t+1}^{d}(e)$ (resp. $\left.L_{f, i, t+1}^{d}(e)\right)$ the amount of domestic (resp. foreign) loans demanded by

\footnotetext{
${ }^{14}$ These lending demand habits are deemed necessary to replicate the dynamic of loans. In the estimation exercise, we use the total stock of loans, they are of different maturities implying a strong autocorrelation. Simply by introducing loan demand habits, taking into account the high autocorrelation of loans becomes tractable easily and does not change the steady state of the model.
} 
entrepreneur $e$ in country $i$. The total cost of loans, $P_{i, t}^{L}$, is thus defined according to,

$$
P_{i, t}^{L}(e)=\left(\left(1-\alpha_{i}^{L}\right) R_{h, t}^{L}(e)^{1-\nu}+\alpha_{i}^{L} R_{f, t}^{L}(e)^{1-\nu}\right)^{1 /(1-\nu)},
$$

where $R_{h, t}^{L}(e)$ (resp. $\left.R_{f, t}^{L}(e)\right)$ is the cost of loans obtained from home (resp. foreign) banks by entrepreneur $e$ in country $i$. The decision to borrow from a particular bank is undertaken on the basis of relative national interest rates,

$L_{h, i, t+1}^{d}(e)=\left(1-\alpha_{i}^{L}\right)\left[\frac{R_{h, t}^{L}(e)}{P_{i, t}^{L}(e)}\right]^{-\nu} L_{i, t+1}^{d}(e)$, and, $L_{f, i, t+1}^{d}(e)=\alpha_{i}^{L}\left[\frac{R_{f, t}^{L}(e)}{P_{i, t}^{L}(e)}\right]^{-\nu} L_{i, t+1}^{d}(e)$

The investment projects undertaken by the entrepreneur are risky and differ with respect to their individual returns. To model individual riskiness, we assume that each project has an individual return equal to $\omega R_{i, t}^{k}$, i.e. that the aggregate return of investment projects in the economy $R_{i, t}^{k}$ is multiplied by a random value $\omega$ (drawn from a Pareto distribution $\left.{ }^{15}\right)$. Defining the value for a profitable project by $\bar{\omega}_{i, t}(e)=$ $E\left(\omega \mid \omega \geq \omega_{i, t}^{C}(e)\right)$ (where $\omega_{i, t}^{C}(e)$ is the critical value of $\omega$ that distinguishes profitable and non profitable projects), the profit function of entrepreneur $e$ after aggregating all projects writes,

$$
\Pi_{i, t+1}^{E}(e)=\left\{\begin{array}{c}
\bar{\omega}_{i, t+1} R_{i, t+1}^{k} Q_{i, t} K_{i, t+1}(e)-P_{i, t}^{L}(e) L_{i, t+1}^{\mathcal{H}}(e) \text { with probability } \eta_{i, t+1}^{E}, \\
0 \text { with probability } 1-\eta_{i, t+1}^{E},
\end{array}\right.
$$

where $\eta_{i, t+1}^{E}$ is the time-varying expected share of gainful projects. Since entrepreneurs cannot screen the value of $\bar{\omega}_{i, t+1}(e)$ ex ante, $\omega_{i, t}^{C}(e)$ cannot be a control variable of the financial contract between borrowers and lenders contrary to Bernanke et al. (1999). To introduce a financial accelerator mechanism, we borrow a concept of De Grauwe (2010) applied in a different context, by assuming that entrepreneurs' forecasts regarding the aggregate profitability of a given project $\bar{\omega}_{i, t}(e)$ are optimistic (i.e., biased upwards $)^{16}$. The perceived ex ante value of profitable projects is defined by the isoleastic function,

$$
g\left(\bar{\omega}_{i, t+1}, \varepsilon_{i, t}^{Q}\right)=\gamma_{i}\left(\bar{\omega}_{i, t+1}\right)^{\frac{\varkappa_{i}}{\left(\varkappa_{i}-1\right)}}\left(e^{\varepsilon_{i, t}^{Q}}\right)^{\frac{1}{\left(\varkappa_{i}-1\right)}},
$$

\footnotetext{
${ }^{15}$ With respect to the standard framework standardly used in the literature (Bernanke et al., 1999), we assume that the heterogeneity in the return of investment project undertaken by firms is modeled using a Pareto distribution. This device commonly used in other branches of the economic literature provides a series of interesting features in the analysis and allows an easier estimation of the financial amplification effect. See B for details about the computation of $\omega$.

${ }^{16}$ Assuming optimistic firms is motivated empirally, Bachmann and Elstner (2013) find evidence of such expectations for German firms using microdata. The optimistic expectations hypothesis of the private sector is very close to the utility functions introduced by Goodhart et al. (2005) for bankers. In our setting, the financial accelerator does not result from a moral hazard problem but rather from a bias in the expectations of the private sector.
} 
where $\varepsilon_{i, t}^{Q}$ is an $A R(1)$ process $^{17}, \varkappa_{i}$ is the elasticity of the external finance premium ${ }^{18}$ and $\gamma_{i}$ is a scale parameter ${ }^{19}$. In this expression, the exogenous shock is affected by exponent $1 /\left(\varkappa_{i}-1\right)$ to normalize to unity the impact of the financial shock $\varepsilon_{i, t}^{Q}$ in the $\log$ deviation form of the model. Thus, ex-ante the entrepreneur chooses a capital value of $K_{i, t+1}(e)$ that maximizes its expected profit defined as,

$$
\max _{\left\{K_{i, t+1}(e)\right\}} \mathbb{E}_{t}\left\{\eta_{i, t+1}^{E}\left[g\left(\bar{\omega}_{i, t+1}, \varepsilon_{i, t}^{Q}\right) R_{i, t+1}^{k} Q_{i, t} K_{i, t+1}(e)-P_{i, t}^{L}(e) L_{i, t+1}^{\mathcal{H}}(e)\right]\right\} .
$$

Using the characteristics of the Pareto distribution, the expected spread required by representative entrepreneur $e$ to undertake the decision to finance firms' investment is,

$$
S_{i, t}(e)=\frac{\mathbb{E}_{t} R_{i, t+1}^{k}}{P_{i, t}^{L}(e)}=\gamma_{i}^{\varkappa_{i}-1}\left[\frac{\kappa}{\kappa-1}\left(1-\frac{N_{i, t+1}(e)}{Q_{i, t} K_{i, t+1}(e)}\right)\right]^{\varkappa_{i}} e^{\varepsilon_{i, t}^{Q}}
$$

The size of the accelerator is determined by the elasticity of the external finance premium $\varkappa_{i}$. For $\varkappa_{i}>0$, the external finance premium is a positive function of the leverage ratio, $Q_{i, t} K_{i, t+1}(e) / N_{i, t+1}(e)$, so that an increase in net wealth induces a reduction of the external finance premium. This phenomenon disappears if $\varkappa_{i}=0$. Concerning the exogenous movements of the external finance premium, a positive realization of $\varepsilon_{i, t}^{Q}$ means that entrepreneurs require a higher expected profitability of capital $E_{t} R_{i, t+1}^{k}$ to finance investment for a given level of lending conditions $P_{i, t}^{L}$. Furthermore, a shock that hits the entrepreneur net wealth $N_{i, t+1}(e)$ will also affect the rentability of the physical capital in the economy. As the rentability of capital is a cost for the intermediate sector, a variation in the net wealth will have aggregate consequences on goods supply through the channel of the capital market as underlined by Gilchrist et al. (2009b). The amount of capital of non-profitable entrepreneurs' investment projects is consumed in terms of home final goods $P_{i, t}\left(1-\eta_{i, t}^{E}\right) \underline{\omega}_{i, t}(e) R_{i, t}^{k} Q_{i, t-1} K_{i, t}(e)$. Thus the net wealth of the entrepreneur in the next period is equal to,

$$
N_{i, t+1}(e)=\left(1-\tau^{E}\right) \frac{\Pi_{i, t}^{E}(e)}{e^{\varepsilon_{i, t}^{N}}},
$$

where $\varepsilon_{i, t}^{N}$ is an exogenous process of net wealth destruction and $\tau^{E}$ is a proportional tax on the profits of the entrepreneur. Anticipating symmetry between entrepreneurs in

\footnotetext{
${ }^{17}$ This shock affects the expected profitability of financial projects by rising in exogeneously the risk premium implying an increase in the cost of capital and hence a reduction in investment as underlined by Gilchrist et al. (2009b) for the US economy.

${ }^{18}$ The elasticity of the external finance premium expresses the degree of bias in estimating the expected rentability of entrepreneurs' projects such that if $\bar{\omega}>1$ and $\varkappa_{i}>0$ then $g(\bar{\omega})>\bar{\omega}$. Expressed $\grave{a}$ la De Grauwe $(2010), \mathbb{E}_{t}^{o p t} \bar{\omega}_{i, t+1}=\mathbb{E}_{t} \gamma_{i}\left(\bar{\omega}_{i, t+1}\right)^{\varkappa_{i} /\left(\varkappa_{i}-1\right)}$ where $\mathbb{E}_{t}^{o p t}$ is the expectation operator of optimistic entrepreneurs.

${ }^{19}$ This parameter is needed to make the steady state independent of $\varkappa_{i}$, such that $\gamma_{i}=\bar{\omega}^{1 /\left(1-\varkappa_{i}\right)}$.
} 
equilibrium and aggregating, the log-linear expression of the external finance premium $S_{i, t}\left(i . e . \hat{s}_{i, t}\right)$ writes as in Bernanke et al. (1999),

$$
\hat{s}_{i, t}=\mathbb{E}_{t} \hat{r}_{i, t+1}^{k}-\hat{p}_{i, t}^{L}=\varkappa_{i}\left(\hat{q}_{i, t}+\hat{k}_{i, t+1}-\hat{n}_{i, t+1}\right)+\varepsilon_{i, t}^{Q}
$$

\section{The Rest of the Model}

This section describes the real component of the model: Households, labour unions, firms, capital suppliers, the authorities and the general equilibrium conditions.

\subsection{Households}

In each economy there is a continuum of identical households who consume, save and work in intermediate firms. The total number of households is normalized to 1 . The representative household $j \in[0,1]$ maximizes the welfare index,

$$
\max _{\left\{C_{i, t}(j), H_{i, t}(j), B_{i, t+1}(j)\right\}} \mathbb{E}_{t} \sum_{\tau=0}^{\infty} \beta^{\tau} e^{\varepsilon_{i, t+\tau}^{\beta}}\left[\frac{\left(C_{i, t+\tau}(j)-h_{i}^{c} C_{i, t-1+\tau}\right)^{1-\sigma_{i}^{c}}}{1-\sigma_{i}^{c}}-\chi_{i} \frac{H_{i, t+\tau}^{1+\sigma_{i}^{L}}(j)}{1+\sigma_{i}^{L}}\right]
$$

subject to,

$$
\frac{W_{i, t}^{h}}{P_{i, t}^{c}} H_{i, t}(j)+R_{t-1} \frac{B_{i, t}(j)}{P_{i, t}^{c}}+\frac{\Pi_{i, t}(j)}{P_{i, t}^{c}}=C_{i, t}(j)+\frac{B_{i, t+1}(j)}{P_{i, t}^{c}}+\frac{T_{i, t}(j)}{P_{i, t}^{c}}+\frac{P_{i, t}}{P_{i, t}^{c}} A C_{i, t}^{B}(j) .
$$

Here, $C_{i, t}(j)$ is the consumption index, $h_{i}^{c} \in[0 ; 1]$ is a parameter that accounts for consumption habits, $H_{i, t}(j)$ is labor effort, $\varepsilon_{i, t}^{\beta}$ is an exogenous $A R(1)$ shock to household preferences. The income of the representative household is made of labor income (with nominal wage, $W_{i, t}^{h}$ ), interest payments for bond holdings, (where $B_{i, t}(j)$ stands for the bonds subscribed in period $t-1$ and $R_{t-1}$ is the gross nominal rate of interest between period $t-1$ an period $t$ ), and earnings $\Pi_{i, t}(j)$ from shareholdings ${ }^{20}$. The representative household spends this income on consumption, bond subscription and tax payments (for a nominal amount of $T_{i, t}(j)$ ). Finally, he has to pay quadratic adjustment costs to buy new bonds (Schmitt-Grohé and Uribe, 2003), according to the function, $A C_{i, t}^{B}(j)=\frac{\mathcal{X}^{B}}{2}\left(B_{i, t+1}(j)-B_{i}(j)\right)^{2}$, where $B_{i}(j)$ is the steady state level of bonds. The first order conditions that solve this problem can be summarized with an

\footnotetext{
${ }^{20}$ The nominal amounts of dividends received from final good producers $\Pi_{i, t}^{y}(j)$ and labor unions $\Pi_{i, t}^{w}(j)$ writes $\Pi_{i, t}(j)=\Pi_{i, t}^{y}(j)+\Pi_{i, t}^{w}(j)$.
} 
Euler bond condition,

$$
\frac{\beta R_{t}}{1+P_{i, t} \mathcal{X}^{B}\left(B_{i, t+1}(j)-B_{i}(j)\right)}=\mathbb{E}_{t}\left\{\frac{e^{\varepsilon_{i, t}^{\beta}}}{e^{\varepsilon_{i, t+1}^{\beta}}} \frac{P_{i, t+1}^{c}}{P_{i, t}^{c}}\left(\frac{\left(C_{i, t+1}(j)-h_{i}^{c} C_{i, t}\right)}{\left(C_{i, t}(j)-h_{i}^{c} C_{i, t-1}\right)}\right)^{\sigma_{i}^{c}}\right\}
$$

and a labor supply function,

$$
\frac{W_{i, t}^{h}}{P_{i, t}^{c}}=\chi_{i} H_{i, t}(j)^{\sigma_{i}^{L}}\left(C_{i, t}(j)-h_{i}^{c} C_{i, t-1}\right)^{\sigma_{i}^{c}}
$$

The consumption basket of the representative household and the consumption price index of country $i$ are, $C_{i, t}(j)=\left(\left(1-\alpha_{i}^{C}\right)^{1 / \mu} C_{h, i, t}(j)^{(\mu-1) / \mu}+\left(\alpha_{i}^{C}\right)^{1 / \mu} C_{f, i, t}(j)^{(\mu-1) / \mu}\right)^{\mu /(\mu-1)}$ and $P_{i, t}^{c}=\left(\left(1-\alpha_{i}^{C}\right) P_{h, t}^{1-\mu}+\alpha_{i}^{C} P_{f, t}^{1-\mu}\right)^{1 /(1-\mu)}$ where $\mu$ is the elasticity of substitution between the consumption of home $\left(C_{h, i, t}(j)\right)$ and foreign $\left(C_{f, i, t}(j)\right)$ goods and $\alpha_{i}^{C}$ is the degree of openness of the economy. In this model, we assume home bias in consumption, so that $\alpha_{i}^{C}<\frac{1}{2}$.

\subsection{Labor Unions}

Households provide differentiated labor types, sold by labor unions to perfectly competitive labor packers who assemble them in a CES aggregator and sell the homogenous labor to intermediate firms. Each representative union is related to an household $j \in[0 ; 1]$. Assuming that the trade union is able to modify its wage with a probability $1-\theta_{i}^{w}$, it chooses the optimal wage $W_{i, t}^{*}(j)$ to maximize its expected sum of profits,

$\max _{\left\{W_{i, t}^{*}(j)\right\}} \mathbb{E}_{t}\left\{\sum_{\tau=0}^{\infty}\left(\theta_{i}^{w} \beta\right)^{\tau} \frac{\lambda_{i, t+\tau}^{c}}{\lambda_{i, t}^{c}}\left[\left(1-\tau^{w}\right) \frac{W_{i, t}^{*}(j)}{P_{i, t+\tau}^{c}} \prod_{k=1}^{\tau}\left(\pi_{i, t+k-1}^{c}\right)^{\xi_{i}^{w}}-\frac{W_{i, t+\tau}^{h}(j)}{P_{i, t+\tau}^{c}}\right] H_{i, t+\tau}(j)\right\}$,

subject to the downgrade sloping demand constraint from labor packers, $H_{i, t+\tau}(j)=$ $\left(W_{i, t}^{*}(j) / W_{i, t+\tau} \prod_{k=1}^{\tau}\left(\pi_{i, t+k-1}^{c}\right)^{\xi_{i}^{w}}\right)^{-\mu_{i, t+\tau}^{w} /\left(\mu_{i, t+\tau}^{w}-1\right)} H_{i, t+\tau}, \forall \tau>0$, where $H_{i, t}(j)$ denotes the quantity of differentiated labor types $j$ that is used in the labor packer production with time-varying substitutability $\mu_{i, t}^{w} /\left(\mu_{i, t}^{w}-1\right)$ between different labor varieties. The first order condition results in the following equation for the re-optimized real wage,

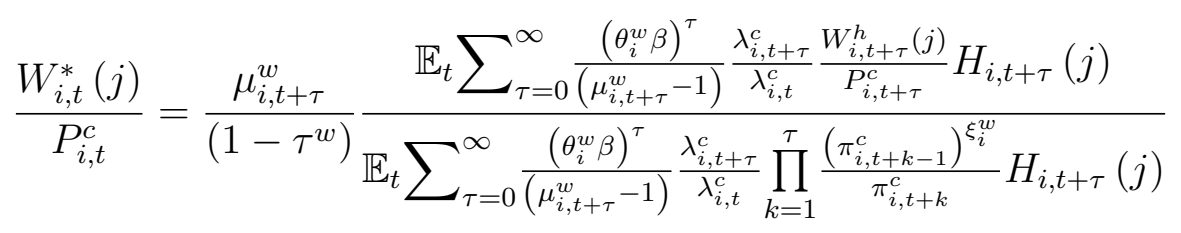

The markup of the aggregate wage over the wage received by the households is taxed by national governments (at rate $\tau_{i}^{w}$ that cancels the markup in steady state (Benigno 
and Woodford, 2005)).

\subsection{Firms}

This sector is populated by two groups of agents: intermediate firms and final firms. Intermediate firms produce differentiated goods $i$, choose labor and capital inputs, and set prices according to the Calvo model. Final goods producers act as a consumption bundler by combining national intermediate goods to produce the homogenous final $\operatorname{good}^{21}$.

Concerning the representative intermediate firm $i \in[0,1]$, it has the following technology, $Y_{i, t}(i)=e^{\varepsilon_{i, t}^{A}} K_{i, t}^{u}(i)^{\alpha} H_{i, t}^{d}(i)^{1-\alpha}$, where $Y_{i, t}(i)$ is the production function of the intermediate good that combines (an effective quantity of) capital $K_{i, t}^{u}(i)$, labor $H_{i, t}^{d}(i)$ and technology $e^{\varepsilon_{i, t}^{A}}$ (an $A R(1)$ productivity shock $)^{22}$. Intermediate goods producers solve a two-stage problem. In the first stage, taking the input prices $W_{i, t}$ and $Z_{i, t}$ as given, firms rent inputs $H_{i, t}^{d}(i)$ and $K_{i, t}^{u}(i)$ in a perfectly competitive factor markets in order to minimize costs subject to the production constraint. The first order condition leads to the marginal cost expression,

$$
M C_{i, t}(i)=M C_{i, t}=\frac{1}{e^{\varepsilon_{i, t}^{A}}}\left(\frac{Z_{i, t}}{\alpha}\right)^{\alpha}\left(\frac{W_{i, t}}{(1-\alpha)}\right)^{(1-\alpha)}
$$

From the cost minimization problem, inputs also satisfy, $\alpha H_{i, t}^{d}(i) W_{i, t}=Z_{i, t} K_{i, t}^{u}(i)(1-\alpha)$.

In the second-stage, firm $i$ sets the price according to a Calvo mechanism. Each period, firm $i$ is not allowed to reoptimize its price with probability $\theta_{i}^{p}$ but price increases of $\xi_{i}^{p} \in[0 ; 1]$ at last period's rate of price inflation, $P_{i, t}(i)=\pi_{i, t-1}^{\xi_{i}^{p}} P_{i, t-1}(i)$. The firm allowed to modify its selling price with a probability $1-\theta_{i}^{p}$ chooses $\left\{P_{i, t}^{*}(i)\right\}$ to maximize its expected sum of profits,

$$
\max _{\left\{P_{i, t}^{*}(i)\right\}} \mathbb{E}_{t}\left\{\sum_{\tau=0}^{\infty}\left(\theta_{i}^{p} \beta\right)^{\tau} \frac{\lambda_{i, t+\tau}^{c}}{\lambda_{i, t}^{c}}\left[\left(1-\tau^{y}\right) P_{i, t}^{*}(i) \prod_{k=1}^{\tau} \pi_{i, t+k-1}^{\xi_{i}^{p}}-M C_{i, t+k}\right] Y_{i, t+\tau}(i)\right\},
$$

under the demand constraint, $Y_{i, t+\tau}(i)=\left(\prod_{k=1}^{\tau} \pi_{i, t+k-1}^{\xi_{i}^{p}} P_{i, t}^{*}(i) / P_{i, t+\tau}\right)^{-\epsilon_{p}} Y_{i, t+\tau}^{d}, \forall \tau>$ 0 , where $Y_{i, t}^{d}$ represents the quantity of the goods produced in country $i, \tau^{y}$ is a pro-

\footnotetext{
${ }^{21}$ Final good producers are perfectly competitive and maximize profits, $P_{i, t} Y_{i, t}^{d}-\int_{0}^{1} P_{i, t}(i) Y_{i, t}(i) \mathrm{d} i$, subject to the production function $Y_{i, t}^{d}=\left(\int_{0}^{1} Y_{i, t}(i)^{\left(\epsilon_{p}-1\right) / \epsilon_{p}} \mathrm{~d} i\right)^{\epsilon_{p} /\left(\epsilon_{p}-1\right)}$. We find the intermediate demand functions associated with this problem are, $Y_{i, t}(i)=\left(P_{i, t}(i) / P_{i, t}\right)^{-\epsilon_{p}} Y_{i, t}^{d}$, $\forall i$. where $Y_{i, t}^{d}$ is the aggregate demand.

${ }^{22} \mathrm{As}$ in Smets and Wouters $(2003,2007)$, we assume that capital requires one period to be settled so that, $K_{i, t}^{u}(i)=u_{i, t} K_{i, t-1}(i)$ given a (variable) level of capital utilization of capital $u_{i, t}$, and a quantity of capital $K_{i, t}(i)$ provided to the intermediate firm in the previous period. Both the level of $u_{i, t}$ and the quantity $K_{i, t}(i)$ are determined below by capital suppliers.
} 
portional tax income on final goods producers' profits which removes the steady state price distortion caused by monopolistic competition (Benigno and Woodford, 2005), $\lambda_{i, t}^{c}$ is the household marginal utility of consumption. The first order condition that defines the price of the representative firm $i$ is,

$$
P_{i, t}^{*}(i)=\frac{\epsilon_{p}}{\left(\epsilon_{p}-1\right)\left(1-\tau^{y}\right)} \frac{\mathbb{E}_{t}\left\{\sum_{\tau=0}^{\infty}\left(\theta_{i}^{p} \beta\right)^{\tau} \frac{\lambda_{i, t+\tau}^{c}}{\lambda_{i, t}^{c}} M C_{i, t+k} Y_{i, t+\tau}(i)\right\}}{\mathbb{E}_{t}\left\{\sum_{\tau=0}^{\infty}\left(\theta_{i}^{p} \beta\right)^{\tau} \frac{\lambda_{i, t+\tau}^{c}}{\lambda_{i, t}^{c}} \prod_{k=1}^{\tau} \pi_{i, t+k-1}^{\xi_{i}^{p}} Y_{i, t+\tau}(i)\right\}} .
$$

\subsection{Capital Suppliers}

Capital suppliers are homogeneous and distributed over a continuum normalized to one. The representative capital supplier $k \in[0 ; 1]$ acts competitively to supply a quantity $K_{i, t+1}(k)$ of capital. Investment is costly, i.e. the capital supplier pays an adjustment cost $A C_{i, t}^{I}(k)$ on investment, such that $A C_{i, t}^{I}(k)=\frac{\mathcal{X}_{i}^{I}}{2}\left(I_{i, t}(k) / I_{i, t-1}(k)-1\right)^{2}$. The capital stock of the representative capital supplier thus evolves according to, $K_{i, t+1}(k)=$ $\left(1-A C_{i, t}^{I}(k)\right) I_{i, t}(k)+(1-\delta) K_{i, t}(k)$. The capital supplier produces the new capital stock $Q_{i, t} K_{i, t+1}(k)$ by buying the depreciated capital $(1-\delta) K_{i, t}(k)$ and investment goods $I_{i, t}(k)$, where $I_{i, t}(k)=\left(\left(1-\alpha_{i}^{I}\right)^{1 / \mu} I_{h i, t}(k)^{(\mu-1) / \mu}+\left(\alpha_{i}^{I}\right)^{1 / \mu} I_{f i, t}(k)^{(\mu-1) / \mu}\right)^{\mu /(\mu-1)}$. In this expression, parameter $\mu$ is the elasticity of substitution between domestic and foreign goods in investment and $\alpha_{i}^{I}$ measures the degree of investment diversification in the monetary union between home and foreign countries. We assume a national bias in investment choices so that, $\alpha_{i}^{I}<0.5$. The price index of investment is, $P_{i, t}^{I}=\left(\left(1-\alpha_{i}^{I}\right)\left(P_{h, t}\right)^{1-\mu}+\alpha_{i}^{I}\left(P_{f, t}\right)^{1-\mu}\right)^{1 /(1-\mu)}$. The representative capital supplier chooses $I_{i, t}(k)$ to maximize profits,

$$
\max _{\left\{I_{i, t}(k)\right\}} \mathbb{E}_{t}\left\{\sum_{\tau=0}^{\infty} \beta^{\tau} \frac{\lambda_{i, t+\tau}^{c}}{\lambda_{i, t}^{c}}\left[Q_{i, t}\left(1-A C_{i, t}^{I}(k)\right)-P_{i, t}^{I}\right] I_{i, t}(k)\right\}
$$

where $\beta^{\tau} \frac{\lambda_{i, t+\tau}^{c}}{\lambda_{i, t}^{c}}$ is the household stochastic discount factor. The price of capital renting thus solves,

$$
Q_{i, t}=P_{i, t}^{I}+Q_{i, t} \frac{\partial\left(I_{i, t}(k) A C_{i, t}^{I}(k)\right)}{\partial I_{i, t}(k)}+\beta \mathbb{E}_{t} \frac{\lambda_{i, t+1}^{c}}{\lambda_{i, t}^{c}} Q_{i, t+1} \frac{\partial\left(I_{i, t+1}(k) A C_{i, t+1}^{I}(k)\right)}{\partial I_{i, t}(k)}
$$

As in Smets and Wouters $(2003,2007)$, capital requires one period to be settled so that, $K_{i, t}^{u}=u_{i, t} K_{i, t-1}$ given a level of capital utilization of capital $u_{i, t}$. Thus, the return from 
holding one unit of capital from $t$ to $t+1$ is determined by,

$$
\frac{\mathbb{E}_{t} R_{i, t+1}^{k}}{1+P_{i, t} \mathcal{X}^{B}\left(B_{i, t+1}(j)-B_{i}(j)\right)}=\mathbb{E}_{t}\left[\frac{Z_{i, t+1} u_{i, t+1}-P_{i, t+1} \Phi\left(u_{i, t+1}\right)+(1-\delta) Q_{i, t+1}}{Q_{i, t}}\right]
$$

where $\Phi\left(u_{i, t+1}\right)$ is the capital utilization cost function. Thus, the optimal capital utilization determines the relationship between capital utilization and the marginal production of capital is defined in $\operatorname{logs}$ by, $\frac{\psi_{i}}{1-\psi_{i}} \hat{u}_{i, t}=\hat{z}_{i, t}$, where $\psi_{i} \in[0 ; 1]$ is the elasticity of utilization costs with respect to capital inputs ${ }^{23}$.

\subsection{Authorities}

National governments finance public spending by charging proportional taxes on profits arising from imperfect competition to compensate price distortions in the steady state and from entrepreneurs net wealth accumulation. Governments also receive a total value of taxes from households. The total amount of public spending, $P_{i, t} G_{i, t}$, is entirely home biased in the $i^{\text {th }}$ economy ${ }^{24}$ and evolves according to an $\mathrm{AR}(1)$ exogenous shock process $P_{i, t} \bar{G} \varepsilon_{i, t}^{G}$. The balance sheet of governments writes,

$$
\begin{aligned}
P_{i, t} \bar{G} \varepsilon_{i, t}^{G} & =\int_{0}^{1} T_{i, t}(j) \mathrm{d} j+\tau^{y} \int_{0}^{1} P_{i, t}(i) Y_{i, t}(i) \mathrm{d} i+\tau^{w} \int_{0}^{1} W_{i, t}(j) H_{i, t}(j) \mathrm{d} j \\
& +\tau^{L} \int_{0}^{1} L_{i, t+1}^{s}(b) R_{i, t}^{L}(b) \mathrm{d} b+\tau^{E} \int_{0}^{1} N_{i, t}^{E}(e) \mathrm{d} e+\tau^{B K} \int_{0}^{1} B K_{i, t}(b) \mathrm{d} b
\end{aligned}
$$

$G_{i, t}$ is the total amount of public spending in the $i^{\text {th }}$ economy that follows and $\operatorname{AR}(1)$ shock process, $\tau^{y}=\left(1-\epsilon_{p}\right)^{-1}, \tau^{w}=\left(1-\mu^{w}\right)$ and $\tau^{L}=\left(1-\mu^{L}\right)$ are taxes that mitigate the negative effects of monopolistic competition in steady states.

The central banks reacts to fluctuations in union wide measures of price and activity growths. The general expression of the interest rule implemented by the monetary union central bank writes,

$$
\frac{R_{t}}{\bar{R}}=\left(\frac{R_{t-1}}{\bar{R}}\right)^{\rho}\left[\left(\pi_{h, t}^{c} \pi_{f, t}^{c}\right)^{\phi^{\pi}}\left(\frac{Y_{h, t} Y_{f, t}}{Y_{h, t-1} Y_{f, t-1}}\right)^{\phi^{\Delta y}}\right]^{\frac{1}{2}(1-\rho)} e^{\varepsilon_{t}^{R}}
$$

where $\varepsilon_{t}^{R}$ is a $\operatorname{AR}(1)$ monetary policy shock process, $\phi^{\pi}$ is the inflation target parameter

\footnotetext{
${ }^{23}$ When households do not take capital supply decisions, the optimal capital utilization is determined by solving, $\max _{u_{i, t}}\left(Z_{i, t} u_{i, t}-\Phi\left(u_{i, t}\right)\right) K_{i, t}$. The utilization choice is defined by the first order condition, $\Phi^{\prime}\left(u_{i, t}\right)=Z_{i, t}$, up to a first-order approximation in deviation from steady states, $\frac{\Phi^{\prime \prime}(u) u}{\Phi^{\prime}(u)} \hat{u}_{i, t}=\hat{z}_{i, t}$.

${ }^{24}$ National public spending are entirely home biased and consists of home varieties, i.e., $P_{i, t} G_{i, t}=$ $P_{i, t}\left(\int_{0}^{1} G_{i, t}(i)^{\left(\epsilon_{p}-1\right) / \epsilon_{p}} \mathrm{~d} i\right)^{\epsilon_{p} /\left(\epsilon_{p}-1\right)}$. The governement demand for home goods writes, $G_{i, t}(i)=$ $\left(\frac{P_{i, t}(i)}{P_{i, t}}\right)^{-\epsilon_{p}} G_{i, t}$
} 
and $\phi^{\Delta y}$ is the GDP growth target.

\subsection{Equilibrium conditions}

In this model, there are in total 8 country specific structural shocks and one common shock in the Taylor rule. For $i \in\{h, f\}$, exogenous disturbances follow a first-order autoregressive process, $\varepsilon_{i, t}^{s}=\rho_{i}^{s} \varepsilon_{i, t-1}^{s}+\eta_{i, t}^{s}$ for $\forall s=\{\beta, A, Q, N, L, B\}$ and one common shock in the Taylor rule, $\varepsilon_{t}^{R}=\rho^{R} \varepsilon_{t-1}^{R}+\eta_{t}^{R}$. For the spending shock process, it is affected by the productivity shock as follows, $\varepsilon_{i, t}^{G}=\rho_{i}^{G} \varepsilon_{i, t-1}^{G}+\eta_{i, t}^{G}+\rho_{i}^{a g} \eta_{i, t}^{A}$; this assumption is empirically motivated as spending also includes net exports, which may be affected by domestic productivity developments (Smets and Wouters, 2007). The wage mark-up disturbance is assumed to follow an $\operatorname{ARMA}(1,1)$ process, $\varepsilon_{i, t}^{W}=\rho_{i}^{W} \varepsilon_{i, t-1}^{W}+\eta_{i, t}^{W}-u_{i}^{W} \eta_{i, t-1}^{W}$, where the MA term $u_{i}^{W}$ is designed to capture the high-frequency fluctuations in wages. Finally, to catch up the co-moment in financial time series, we add common financial shocks $\eta_{t}^{s}$ for $\forall s=\{Q, N, L, B\}$. We denote by $\rho_{i}^{\beta}, \rho_{i}^{A}, \rho_{i}^{G}, \rho_{i}^{Q}, \rho_{i}^{N}, \rho_{i}^{L}, \rho_{i}^{W}, \rho_{i}^{B}$ and $\rho^{R}$ the autoregressive terms of the exogenous variables, $\eta_{i, t}^{\beta}, \eta_{i, t}^{A}, \eta_{i, t}^{G}, \eta_{i, t}^{Q}, \eta_{i, t}^{N}, \eta_{i, t}^{L}, \eta_{i, t}^{W}, \eta_{i, t}^{B}$ and $\eta_{t}^{Q}, \eta_{t}^{N}, \eta_{t}^{L}, \eta_{t}^{B}, \eta_{t}^{R}$ are standard errors that are mutually independent, serially uncorrelated and normally distributed with zero mean and variances $\sigma_{i, \beta}^{2}, \sigma_{i, A}^{2}, \sigma_{i, G}^{2}, \sigma_{i, Q}^{2}, \sigma_{i, N}^{2}$, $\sigma_{i, L}^{2}, \sigma_{i, W}^{2}, \sigma_{i, B}^{2}$ and $, \sigma_{Q}^{2}, \sigma_{N}^{2}, \sigma_{L}^{2}, \sigma_{B}^{2}, \sigma_{R}^{2}$ respectively. A general equilibrium is defined as a sequence of quantities $\left\{\mathcal{Q}_{t}\right\}_{t=0}^{\infty}$ and prices $\left\{\mathcal{P}_{t}\right\}_{t=0}^{\infty}$ such that for a given sequence of quantities $\left\{\mathcal{Q}_{t}\right\}_{t=0}^{\infty}$ and the realization of shocks $\left\{\mathcal{S}_{t}\right\}_{t=0}^{\infty}$, the sequence $\left\{\mathcal{P}_{t}\right\}_{t=0}^{\infty}$, guarantees the equilibrium on the capital, labor, loan, intermediate goods and final goods markets.

After $(i)$ aggregating all agents and varieties in the economy, (ii) imposing market clearing for all markets, $($ iii $)$ assuming that countries are mirror images of one another in terms of market openness ${ }^{25}$, (iv) substituting the relevant demand functions, the resource constraint for the home country reads as follows,

$$
\begin{aligned}
\frac{Y_{h, t}}{\Delta_{h, t}^{p}} & =\left(1-\alpha^{C}\right)\left(\frac{P_{h, t}}{P_{h, t}^{c}}\right)^{-\mu} C_{h, t}+\alpha^{C}\left(\frac{P_{h, t}}{P_{f, t}^{c}}\right)^{-\mu} C_{f, t} \\
& +\left(1-\alpha^{I}\right)\left(\frac{P_{h, t}}{P_{h, t}^{I}}\right)^{-\mu}\left(1+A C_{h, t}^{I}\right) I_{h, t}+\alpha^{I}\left(\frac{P_{h, t}}{P_{f, t}^{I}}\right)^{-\mu}\left(1+A C_{f, t}^{I}\right) I_{f, t} \\
& +\bar{G} \varepsilon_{h, t}^{G}+A C_{h, t}^{B}+\left(1-\eta_{h, t}^{E}\right) \underline{\omega}_{h, t} Q_{h, t} K_{h, t}+\Phi\left(u_{h, t}\right) K_{h, t-1},
\end{aligned}
$$

where $\Delta_{i, t}^{p}=\int_{0}^{1}\left(P_{i, t}(i) / P_{i, t}\right)^{-\epsilon_{p}} \mathrm{~d} i$ is the price dispersion term ${ }^{26}$. The aggregation of

\footnotetext{
${ }^{25} i . e, \alpha_{h}^{s}=\alpha^{s} \Leftrightarrow \alpha_{f}^{s}=\left(1-\alpha^{s}\right)$ for markets $s=C, I, L, I B$ and the two countries are of equal size.

${ }^{26}$ To close the model, additional costs are entirely home biased, i.e. adjustment costs on bonds $A C_{i, t}^{B}=\left(\int_{0}^{1} A C_{i, t}^{B}(i)^{\left(\epsilon_{p}-1\right) / \epsilon_{p}} \mathrm{~d} i\right)^{\epsilon_{p} /\left(\epsilon_{p}-1\right)}$, insolvent investment projects of entrepreneurs and capital
} 
prices of the final goods sector leads to the expression,

$$
P_{i, t}^{1-\epsilon_{p}}=\theta_{i}^{p}\left(P_{i, t-1} \pi_{i, t-1}^{\xi_{i}^{p}}\right)^{1-\epsilon_{p}}+\left(1-\theta_{i}^{p}\right)\left(P_{i, t}^{*}\right)^{1-\epsilon_{p}} .
$$

Concerning unions, the aggregation of unions allowed and not allowed to reoptimize leads to the following expression of the aggregate wage index,

$$
W_{i, t}^{\frac{1}{1-\mu_{i, t}^{w}}}=\theta_{i}^{w}\left[W_{i, t-1}\left(\pi_{i, t-1}^{C}\right)^{\xi_{i}^{w}}\right]^{\frac{1}{1-\mu_{i, t}^{w}}}+\left(1-\theta_{i}^{w}\right)\left(W_{i, t}^{*}\right)^{\frac{1}{1-\mu_{i, t}^{w}}}
$$

and the equilibrium on this market reads, $\int_{0}^{1} H_{i, t}(j) \mathrm{d} j=\Delta_{i, t}^{w} \int_{0}^{1} H_{i, t}^{d}(i) \mathrm{d} i$, where $\Delta_{i, t}^{w}=$ $\int_{0}^{1}\left(\frac{W_{i, t}(j)}{W_{i, t}}\right)^{-\mu_{i, t}^{w} /\left(\mu_{i, t}^{w}-1\right)} \mathrm{d} j$ is the wage dispersion term between different labor types.

The equilibrium on the home loan market reads,

$$
L_{h, t+1}^{s}=\left(\left(1-\alpha^{L}\right)\left[\frac{R_{h, t}^{L}}{P_{h, t}^{L}}\right]^{-\nu} L_{h, t+1}^{d}+\alpha^{L}\left[\frac{R_{h, t}^{L}}{P_{f, t}^{L}}\right]^{-\nu} L_{f, t+1}^{d}\right) \Delta_{h, t}^{L},
$$

where $\Delta_{i, t}^{L}=\int_{0}^{1}\left(\frac{R_{i, t}^{L}(b)}{R_{i, t}^{L}}\right)^{-\mu_{i, t}^{L} /\left(\mu_{i, t}^{L}-1\right)} \mathrm{d} b$ is the dispersion term of credit rates in the economy. The aggregation of loan prices writes,

$$
\left(R_{i, t}^{L}\right)^{\frac{1}{1-\mu_{i, t}^{L}}}=\theta_{i}^{L}\left(R_{i, t-1}^{L}\left(\frac{R_{i, t-1}^{L}}{R_{i, t-2}^{L}}\right)^{\xi_{i}^{L}}\right)^{\frac{1}{1-\mu_{i, t}^{L}}}+\left(1-\theta_{i}^{L}\right)\left(R_{i, t}^{L}\right)^{\frac{1}{1-\mu_{i, t}^{L}}}
$$

On the perfectly competitive interbank market, the market clears when the following condition holds,

$$
I B_{h, t+1}^{s}=\frac{\lambda}{1-\lambda}\left(\left(1-\alpha^{I B}\right)\left[\frac{R_{h, t}^{I B}}{P_{h, t}^{I B}}\right]^{-\xi} I B_{h, t+1}^{d}+\alpha^{I B}\left[\frac{R_{h, t}^{I B}}{P_{f, t}^{I B}}\right]^{-\xi} I B_{f, t+1}^{d}\right)
$$

Asset market equilibrium implies that the world net supply of bonds is zero, the same applies to current accounts excess and deficits, $B_{h, t+1}+B_{f, t+1}=0$ and $C A_{h, t}+C A_{f, t}=0$, where home current account dynamic reads as follow,

$$
\begin{aligned}
C A_{h, t} & =\left(B_{h, t+1}-B_{h, t}\right)+\left[\left(L_{h, f, t+1}-L_{h, f, t}\right)-\left(L_{f, h, t+1}-L_{f, h, t}\right)\right] \\
& +\left[\left(I B_{h, f, t+1}-I B_{h, f, t}\right)-\left(I B_{f, h, t+1}-I B_{f, h, t}\right)\right] .
\end{aligned}
$$

utilization costs from capital suppliers $K_{i, t}=\left(\int_{0}^{1} K_{i, t}(i)^{\left(\epsilon_{p}-1\right) / \epsilon_{p}} \mathrm{~d} i\right)^{\epsilon_{p} /\left(\epsilon_{p}-1\right)}$. The demands associated with the previous costs are, $A C_{i, t}^{B}(i)=\left(P_{i, t}(i) / P_{i, t}\right)^{-\epsilon_{p}} A C_{i, t}^{B}, K_{i, t}(i)=\left(P_{i, t}(i) / P_{i, t}\right)^{-\epsilon_{p}} K_{i, t}$. 


\section{Estimation}

\subsection{Data}

The model is estimated with Bayesian methods on Euro Area quarterly data over the sample period 1999Q1 to 2013Q3. The dataset includes 17 time series as presented in A: real GDP, real consumption, real investment, the ECB refinancing operation rate, the HICP, the real unit labor cost index, the real index of notional stocks of corporate and interbank loans, and the real borrowing cost of non-financial corporations. Data with a trend are made stationary using a linear trend and are divided by the population. We also demean the data because we do not use the information contained in the observable mean. Fig. 4 plots the transformed data.
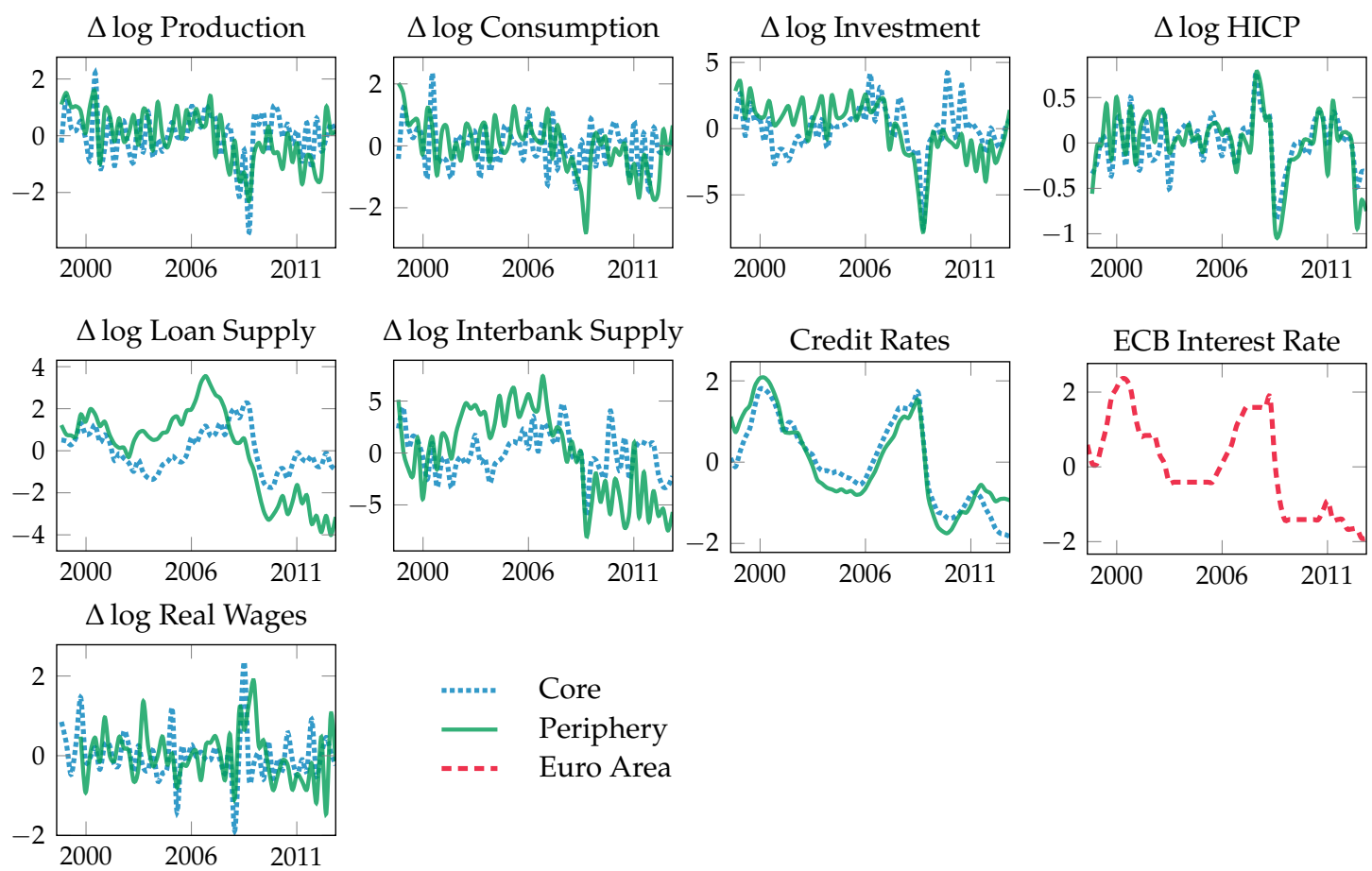

Figure 4: Observable variables used in the estimation

\subsection{Calibration and Prior Distribution of Parameters}

We fix a small number of parameters commonly used in the literature of real business cycles models in Table 1 . These include the quarterly depreciation rate $\delta$, the quarterly discount factor $\beta$, the capital share in the production $\alpha$, the steady state of government expenditures in output $\bar{G} / \bar{Y}$ and the adjustment cost on portfolio $\mathcal{X}^{B}$ (Schmitt-Grohé and Uribe, 2003). Under this calibration, the share of consumption and investment in the GDP is $56 \%$ and $20 \%$ respectively which is consistent with the Euro Area. 


\begin{tabular}{lll} 
Parameter & Value & Description \\
\hline \hline$\beta$ & 0.995 & Discount factor \\
$\delta$ & 0.02 & Depreciation rate \\
$\alpha$ & 0.25 & Capital share \\
$\bar{H}$ & $1 / 3$ & Share of hours worked per day \\
$\mathcal{X}^{B}$ & $0.07 \%$ & Portfolio adjustment costs \\
$\bar{G} / \bar{Y}$ & 0.24 & Spending to GDP ratio \\
$\bar{N} / \bar{K}$ & 0.40 & Net worth to capital ratio \\
$\overline{I B} / \bar{L}$ & 0.20 & Interbank funds to lending ratio \\
$\overline{B K} / \bar{L}$ & 0.10 & Bank capital to lending ratio \\
$\bar{R}^{L}-\bar{R}$ & $0.02^{0.25}$ & Loan spread \\
\hline \hline
\end{tabular}

Table 1: Calibration of the model (all parameters are quarterly)

Regarding financial parameters, we fix the net worth to capital ratio of the private sector on the findings of Gerali et al. (2010), while the spread between the lending rate and the refinancing rate is calculated on the average observable variables used in the estimation for France and Germany and has a value of 200 points basis annually. We suppose that in steady state, the interbank rate in the Euro Area is equal to the refinancing rate $R=R_{h}^{I B}=R_{f}^{I B}$. Recall that following the Pareto distribution $\omega \sim \mathcal{P}\left(\kappa ; \omega_{\min }\right)$ where $\kappa$ is the shape parameter and $\omega_{\min }$ the minimum value of $\omega \in\left[\omega_{\min } ;+\infty[\right.$. When $\omega^{C}$ hits the lower bound ( $\omega^{C}=\omega_{\text {min }}$ ), the economy is riskless implying $R^{k}=R^{L}=R$ so that when $\omega^{C}>\omega_{\min }$ there are financial frictions and defaulting entrepreneurs projects in the steady state. Given the first order condition of banks $R^{L}=R / \eta$, the conditions $E[\omega]=1=\frac{\omega_{\min } \kappa}{\kappa-1}$ and the definition of the share of gainful projects $\eta=\left(\omega_{\min } / \omega^{C}\right)^{\kappa}$, we compute $\kappa$ and $\omega_{\min }$ via the following condition $\omega_{\min }=(\kappa-1) / \kappa=1-\bar{N} / \bar{K}$. Calibrating the model without financial frictions $\left(\omega=\omega_{\min }\right)$ and without loans $(L=0)$ makes the model really close to the Smets and Wouters model in a two-country set-up. From the previous calibration, we get the quarterly entrepreneur failure rate of $\eta=1.2 \%$, which is comparable to Bernanke et al. (1999).

Our priors are listed in Table 4. Overall, they are either consistent with the previous literature or relatively uninformative. For a majority of new Keynesian models' parameters, i.e. $\sigma_{i}^{c} . . \sigma_{i}^{L}, h_{i}^{c}, \theta_{i}^{p}, \theta_{i}^{w}, \xi_{i}^{p}, \xi_{i}^{w}, \mathcal{X}_{i}^{I}, \psi_{i}, \phi^{\pi}, \phi^{\Delta y}$ and shocks processes parameters, we use the prior distributions chosen by Smets and Wouters (2003, 2007). Concerning international macroeconomic parameters, our priors are largely inspired by Lubik and Schorfheide (2006) for substitution parameters $\mu, \nu$ and $\xi$. Regarding market openness, we use priors that are close to the observed degrees of openness: $\alpha^{C}, \alpha^{I}, \alpha^{L}$ and $\alpha^{I B}$ have a beta prior of means $0.10,0.08,0.08$ and 0.20 and standard deviations of 0.04 , 0.04, 0.04 and 0.07 respectively. For Calvo credit rates parameters, our priors are the same as the Calvo price priors. We set the prior for the elasticity of the external finance 
premium $\varkappa_{i}$ to a normal distribution with prior mean equal to 0.10 and standard deviation 0.05 consistent with previous financial accelerator estimations (De Graeve, 2008; Gilchrist et al., 2009a). For loan demand habits for firms and banks, we chose a very uninformative prior of mean 0.50 and standard deviation 0.20 with a beta distribution. Finally, the monitoring cost is set to a normal distribution with mean 0.50 and variance 0.20 which is consistent with Cúrdia and Woodford (2010).

\subsection{Posterior Estimates}

The methodology is standard to the Bayesian estimation of DSGE models ${ }^{27}$. Fig. 5 reports the prior and posterior marginal densities of the parameters of the model, excluding the standard deviation of the shocks and the parameters driving the shocks processes. In Fig. 5, the data were relatively informative except for a small numbers of parameters for which the posterior distribution stay very close to the chosen priors. These parameters are the risk consumption parameter $\sigma_{i}^{c}$, the elasticity of the external premium for peripheral countries $\varkappa_{f}$, the inflation and GDP growth penalization degrees in the Taylor rule $\phi^{\pi}$ and $\phi^{\Delta y}$, the elasticity for loans $\xi, \nu$ and the financial openness $\alpha^{L}$ for the corporate sector ${ }^{28}$. We investigate the sources of non identification for these parameters using methods developed by Saltelli et al. (2008), Andrle (2010) and Iskrev (2010). We find that the low identification of parameters driving the risk aversion coefficient $\sigma_{i}^{c}$ and the substitutions of loans $\nu$ and $\xi$ is due to their small impacts on the likelihood. As An and Schorfheide (2007), we find that the the Taylor rule smoothing $\rho$ is the best identified parameter, and that it strongly interacts with other parameters in the Taylor rule $\phi^{\pi}$ and $\phi^{\Delta y}$. Indeed, using the brute force search à la Iskrev (2010), we note a correlation link that involves $\phi^{\pi}, \phi^{\Delta y}$ with $\rho^{29}$. We also find a partial con-

\footnotetext{
${ }^{27}$ Interest rates data are associated with one-year maturity loans, we take into account this maturity by multiplying by 4 the rates in the measurement equation. The number of shocks is higher (or equal) to observable variables to avoid stochastic singularity issue. Recalling that $i \in\{h, f\}$, the vectors of observables $\mathcal{Y}_{t}^{\text {obs }}=$ $\left[\Delta \log \tilde{Y}_{i, t}, \Delta \log \tilde{C}_{i, t}, \Delta \log \tilde{I}_{i, t}, R_{t}, \Delta \log H I C P_{i, t}, \Delta W_{t}, \Delta \tilde{L}_{i, t}^{s}, R_{i, t}^{L}, \Delta \widetilde{I B}_{i, t}^{s}\right]^{\prime}$ and measurement equations $\mathcal{Y}_{t}=\left[\hat{y}_{i, t}-\hat{y}_{i, t-1}, \hat{c}_{i, t}-\hat{c}_{i, t-1}, \hat{\imath}_{i, t}-\hat{\imath}_{i, t-1}, 4 \times \hat{r}_{t}, \hat{\pi}_{i, t}^{c}, \hat{w}_{t}-\hat{w}_{t-1}, \hat{l}_{i, t}^{s}-\hat{l}_{i, t-1}^{s}, 4 \times \hat{r}_{i, t}^{L}, \widetilde{i b}_{i, t}^{s}-\widetilde{i b}_{i, t-1}^{s}\right]^{\prime}$, where $\Delta$ denotes the temporal difference operator, $\tilde{X}_{t}$ is per capita variable of $X_{t}$. The model matches the data setting $\mathcal{Y}_{t}^{o b s}=\overline{\mathcal{Y}}+\mathcal{Y}_{t}$ where $\overline{\mathcal{Y}}$ is the vector of the mean parameters, we suppose this is a vector of all 0 . The posterior distribution combines the likelihood function with prior information. To calculate the posterior distribution to evaluate the marginal likelihood of the model, the MetropolisHastings algorithm is employed. To do this, a sample of 400,000 draws was generated, neglecting the first 50,000. The scale factor was set in order to deliver acceptance rates of between 20 and 30 percent. Convergence was assessed by means of the multivariate convergence statistics taken from Brooks and Gelman (1998).

${ }^{28}$ The elasticity of intertemporal substitution, inflation weight and output growth in the monetary policy rule are parameters that are frequently not well identified, see for exemple An and Schorfheide (2007) or Kolasa (2008).

${ }^{29}$ See An and Schorfheide (2007) for further explanations on this correlation link.
} 


\begin{tabular}{lcccc}
\hline \hline & w/ common financial shocks & \multicolumn{2}{c}{ w/o common financial shocks } \\
& $\mathcal{M}_{1}(\theta)$ & $\mathcal{M}_{2}(\theta)$ & $\mathcal{M}_{1}(\theta)$ & $\mathcal{M}_{2}(\theta)$ \\
& autarky & globalization & autarky & globalization \\
\hline Prior probability & $1 / 2$ & $1 / 2$ & $1 / 2$ & $1 / 2$ \\
Laplace approximation & -1392.0 & -1389.5 & -1432.1 & -1412.1 \\
Posterior odds ratio & 1.00 & 13.5 & 1.00 & $4.7 \times 10^{8}$ \\
Posterior model probability & 0.07 & 0.93 & 0 & 1.00 \\
\hline \hline
\end{tabular}

Table 2: Prior and posterior model probabilities

founding with the elasticity of the external premium $\varkappa_{f}$ and the credit rate stickiness $\theta_{f}^{L}$ : since the external finance premium is mainly driven by the monetary policy shock (De Graeve, 2008), the introduction of Calvo credit rate weakens the identification of the external finance premium as monetary policy shocks are dampened when rates are sticky. Finally, even if the market openness $\alpha^{L}$ stay very close to the prior, identification methods show that $\alpha^{L}$ is accurately identified (even better than $\left.\alpha^{C}\right)^{30}$.

The posterior parameters' differences or similarities between core and peripheral countries provide the microfoundations for national asymmetries as shown in Table 4 and in Table 3. Concerning shocks parameters, there is one noticeable difference between core and periphery in the persistence of riskiness shocks, any change in the expectations of the private sector lasts more in periphery. Regarding structural parameters, real frictions are more important in periphery as consumption habits, capital utilization elasticity and investment costs are higher. Turning to nominal frictions, core and periphery face similar price rigidities as Calvo and indexation parameters for prices are nearly equal, while wage rigidities are more pronounced in core countries. Finally for financial frictions, the pass-through of the policy rate is not surprisingly better in core countries as Calvo and indexation parameters for credit rate are lower than in periphery. According to the elasticity of external premium, peripheral firms are more optimistic than core. The monitoring technology is better for peripheral liquid banks. For the Euro area parameters, the banking system is composed of $25 \%$ of banks in need of interbank funds. Concerning market openness parameters, they are consistent with the data and close to the findings of Eyquem and Poutineau (2010) for $\alpha^{C}$ and $\alpha^{I}$ while the market openness of the interbank market is a slightly lower than its value observed in Fig. 2.

Since we are interested in finding evidence that cross-border loans significantly explain a part of the business cycles, we consider $\theta$ the vector of the estimated parameters of the model $\mathcal{M}(\theta)$ presented in Section 3 and we estimate $\mathcal{M}(\theta)$ under two scenarii: in $\mathcal{M}_{1}(\theta)$ there is no cross-border lending flows between countries so that, $\alpha^{L}=\alpha^{I B}=0$, $\nu=\xi=0$; in $\mathcal{M}_{2}(\theta)$ we introduce cross-border lending flows between countries by

\footnotetext{
${ }^{30}$ Parameter $\alpha^{L}$ does not involve any important correlation link with other parameter, its loglikelihood is not flat and is not a weak element of the parameter set.
} 
estimating $\alpha^{L}, \alpha^{I B} \in[0 ; 1], \nu, \xi \geq 0$. At last, we are interested in finding evidence that cross-border loans significantly explain a part of the business cycles of the Eurozone. Put differently, we examine the hypothesis $H_{0}: \alpha^{L}=\alpha^{I B}=0, \nu=\xi=0$ against the hypothesis $H_{1}: \alpha^{L}, \alpha^{I B} \in[0 ; 1), \nu, \xi>0$, to do this we evaluate the posterior odds ratio of $\mathcal{M}_{2}(\theta)$ on $\mathcal{M}_{1}(\theta)$ using Laplace-approximated marginal data densities. The posterior odds of the null hypothesis of no significance of banking flows is 13.5:1 which leads us to strongly reject the null, i.e. cross-border lending flows do matter in explaining the business cycles of the Euro Area. This result is confirmed in terms of log marginal likelihood. When the models are estimated without common financial shocks, then cross-border flows have an even more important role in explaining the business cycles as the posterior odds ratio becomes $4.7 \times 10^{8}: 1$.

\section{The Consequences of Cross-border Loans}

Once the model has been estimated, we evaluate the consequences of cross-border lending on the national and international transmission of asymmetric shocks. We report the Bayesian IRFs obtained from linearized models $\mathcal{M}_{1}$ and $\mathcal{M}_{2}$. We concentrate on three main shocks that affect the core countries: an asymmetric productivity shock affecting firms, an asymmetric financial shock that reduces the net worth of entrepreneurs and a positive shock affecting the liquidity situation of the banking system.

\subsection{A Positive Shock on Total Factor Productivity}

Fig. 6 reports the simulated responses of the main macroeconomic and financial variables following a positive shock to $\varepsilon_{h, t}^{A}$ equal in size to the standard deviation of total factor productivity estimated in Table 4.

In the benchmark situation (dotted line), loan markets are segmented. As standardly documented in the literature, this productivity shock increases production, consumption and investment while decreasing the inflation rate in the core countries (Smets and Wouters, 2003). This shock is transmitted to peripheral economies through the terms of trade, the current account and the reaction of the central bank interest rate. The deterioration of the core countries' terms of trade increases the relative competitiveness and the exports of core countries goods towards peripheral economies. The decrease of the relative price of core countries goods depresses peripheral activity and investment. The average union wide rate of consumption price inflation decreases, which leads the central bank to reduce the interbank interest rate (Eyquem and Poutineau, 2010). As observed, corporate loans increase in both countries. In core countries, entrepreneurs 
contract more loans to finance new investment flows after the positive supply shock. Central bank reaction affects the banking system through the decrease of the interest rate. This, in turn, lowers the interest rate on loans and increases corporate loan demand. As observed, interbank lending also rises to allow illiquid banks to meet the increased corporate loan demand. This increase in corporate loan demand dampens the decrease in investment as all the new loans remain in the periphery. However the rise in firm leverage increases the failure rate of investment projects in both countries and by so, the interest rate served by banks increases after 5 quarters. Thus, the segmentation of the loan market has a clear dampening effect in the periphery with regards to the transmission of core countries' productivity shocks.

The possibility of banks to engage in cross-border lending (plain lines) acts as a mechanism that mainly increases the dispersion of investment cycles in the monetary union. As cross-border lending improves the international allocation of financial resources in the monetary union, it amplifies the positive impact on investment in core countries and the negative impact in the peripheral economies, while leaving unaffected the dynamics of consumption and activity in both part of the monetary union. As a consequence, the current account adjustment (that reflects net savings) is significantly affected by the assumption regarding the degree of cross-border banking. Part of the increase in domestic investment is fuelled by foreign loans: the increase in foreign lending increases (partly financed by an increase in interbank lending in the peripheral countries). This implies a net increase in foreign loan supply after 5 quarters with regard to the segmented situation. By lending to more productive domestic firms, the foreign banking system has access to more reliable borrowers. Cross-border lending clearly impacts negatively the foreign macroeconomic performance, as more lending resources are diverted towards the domestic economy. This is clearly shown by the increased slump in peripheral countries' investment. With cross-border relations, the increase in interbank lending is reflected by a decrease in core countries' loan supply. Part of the liquidity of domestic banks comes from peripheral banks, through cross-border interbank lending.

Cross-border lending significantly affects the dynamics of the current account. Ignoring cross-border banking, the adjustment of the current account is standard, as the domestic economy experiences a surplus of net exports, that depicts the intertemporal allocation of the increase in national resources over a sample time period of thirty quarters. Cross-border loans clearly deteriorate core countries' current account with respect to the benchmark situation (dotted lines). As activity and consumption remain unaffected by the integration of the loan market, and as the increase of investment is higher in the core countries (while the decrease in investment is higher in peripheral countries), the current account of core countries deteriorates with respect to the segmented situation, to reflect the increased dispersion of investment cycles. Finally, the IRFs of 
the terms of trade and of the central bank interest rate are unaffected by cross-border lending.

\subsection{A Negative Shock on Firms Net Worth}

The second set of IRFs, reported in Fig. 7, describes the consequences of a negative shock on core countries' firm net worth $\varepsilon_{h, t}^{N}$. This negative shock can be thought of as an overnight decrease in the value of investor capital (following, for example a stock exchange collapse).

Without cross-border loans (dotted lines), a reduction in firms' net worth depresses investment and production and is deflationary in core countries. The reduction of activity is driven by the decrease in investment decisions. The central bank reacts to deflation by decreasing the interbank interest rate. This, in turn, increases consumption and dampens the negative impact on core countries' investment after 4 periods. As investment decreases more than activity, consumption increases and, as core countries' inflation rate decreases more than peripheral inflation rate, the domestic terms of trade deteriorates. As a consequence, more domestic goods are exported and consumed by peripheral households. The production of foreign goods decreases which, in turn, implies a decrease in investment decisions. In the meanwhile, following the decrease in the ECB central bank interest rate, peripheral consumption increases (this increase falls on imported goods). Initially, the negative wealth shock increases the probability of insolvent projects, and leads to higher interest rates on loans, despite the reduction of the central bank interest rate. This, in turn depresses investment. As observed, since banks engage in less corporate loans, their liquidity situation improves and interbank lending decreases. The improvement in core countries' current account reflects the increase in net savings coming from the decrease of investment in this part of the monetary union. Finally, interbank loans remain almost unaffected in peripheral countries.

Cross-border bank activity (plain lines) acts as a mechanism that amplifies the negative financial shock in core countries while it improves the situation of the periphery. The positive impact observed on peripheral investment comes from the fact that part of core countries's loans are diverted towards the periphery. This net inflow of loans in the periphery fuels firm investment. The second phenomenon is the drop in interbank loans: now part of corporate loans is directly distributed by core countries' banks to peripheral entrepreneurs. This phenomenon is reinforced by the fact that the borrowing cost of corporate loans is cheaper in the periphery with cross border loans, with respect to the segmented situation. Thus, as banks engage in cross-border loans towards peripheral firms, they lend less to core countries' firms, which furthermore depresses investment and activity in this part of the monetary union. 
Taken globally, the macroeconomic performance of the currency union worsens with cross-border bank lending, as activity slightly decreases with respect to the segmented situation. The combination of a higher deterioration of the core countries terms of trade and decrease in domestic investment improves the current account of core countries. Thus cross-border lending clearly amplifies the diffusion of a negative net worth shock in the monetary union. It also increases the heterogeneity of investment cycles and the dispersion of current account positions. Negative consequences of net worth shocks have already been studied in the literature with financial globalization (Ueda, 2012) and without (Hirakata et al., 2011). Our results are in line with this literature.

\subsection{A Positive Shock on Bank Resources}

The third set of IRFs, reported in Fig. 8, describes the consequences of a positive shock on bank resources $\varepsilon_{h, t}^{l i a b}$. This positive shock represents an increase in the resources of the core countries' banking system. It improves the liquidity situation of the core countries' banking system which in turn implies the creation of more corporate loans and reduces the need for interbank loans.

Without cross-border loans (dotted lines), this shock induces an increase in core countries' investment, which in turn leads to more activity. However, as it generates a positive demand shock (the increase in investment is higher than that of activity), it leads to more inflation and to an initial improvement in the terms of trade of core countries. This last phenomenon deteriorates the price competitiveness of core countries' goods while increasing that of peripheral goods. As a consequence, activity increases in the peripheral economies. In the meanwhile as this shock implies an increase in the average inflation rate of the monetary union, the central bank reacts by increasing its interest rate, which in turn depresses consumption and leads to a decrease in activity and inflation after 5 periods in core countries. Lending decisions in the periphery can be explained as follows: the increase in the interest rate of the central bank affects positively the interest rate on loans which in turn depresses loan demand in the periphery. As a consequence, the increase in peripheral investment is financed by peripheral entrepreneur net wealth.

Cross-border bank activity (plain lines) acts as a mechanism that amplifies the transmission of the core country shock on peripheral countries' investment. Now, peripheral entrepreneurs have access to domestic corporate loans which increases peripheral investment. With cross-border lending, interbank developments should be understood as follows: the further decrease in interbank loans and higher increase in peripheral countries interbank lending clearly fuels investment in the periphery. The increase in the supply of corporate loans is channelled though the increase in interbank lending and 
the increase in cross-border bank lending (more decrease in the core countries' interbank loans). Initially more corporate loans are distributed in the periphery. However, as it leads to an increase in the leverage ratio of firms, it increases the probability of unproductive projects and, by so, increases the interest rate on loans after 4 periods. This, in turn, depresses peripheral investment after 4 periods.

Cross border banking impacts the dynamics of the bilateral current account. As the dynamics of investment in the periphery is reversed between segmented and integrated situations, it clearly affects the time path of investment and, by so, the time path of the current account. This reaction of investment more than compensate the impact of the terms of trade improvement that leads to the current account deficit in the situation with segmented loan markets.

\section{$7 \quad$ The Driving Forces of Business and Credit Cycles}

\subsection{The Historical Variance Decomposition}

Table 5 reports the posterior variance decomposition of the main aggregates (rate of growth of activity, consumption, investment and loan supply), the average interest rate paid by borrowers, the interest rate of the central bank and the current account. To evaluate the consequences of cross-border interbank and corporate loans, we contrast the variance decomposition reported for model $\mathcal{M}_{2}$ with corresponding benchmark figures reported for $\mathcal{M}_{1}$ under loan market segmentation. To see the role played by the shocks on these evolutions, we decompose each aggregate variations into the proportions explained by supply shocks (we aggregate $\eta_{i, t}^{A}$ and $\eta_{i, t}^{W}$ ), demand shocks (we aggregate $\eta_{i, t}^{\beta}$ and $\eta_{i, t}^{G}$ ), financial shocks (we aggregate $\eta_{i, t}^{N}, \eta_{i, t}^{Q}, \eta_{i, t}^{B}$ and $\eta_{i, t}^{L}$ ) and the monetary policy $\operatorname{shock}\left(\eta_{t}^{R}\right)$.

As reported, most of the variance of the growth rate of activity, consumption and inflation is explained by real supply shocks, while the variance of investment, loan supply and interest rates are mainly affected by national financial shocks. These results are in line with the ones reported by Hirakata et al. (2011). Remarkably, the contribution of financial shocks to the fluctuations in the rate of interbank and corporate loan growth rate are comparable (respectively around $46 \%$ and $48 \%$ ).

Besides these general features, our model reports national heterogeneities regarding financial and real supply shocks. On average, financial shocks have a higher impact on core countries' variables than on peripheral variables. As an example, the contribution of the financial shocks accounts respectively for $14.6 \%$ and $1.7 \%$ of the variance of activity and consumption in core countries, while it accounts for respectively $10.0 \%$ and 
$1.2 \%$ in the periphery. As a main noticeable exception core investment is less affected by financial shock than peripheral investment (50.1\% instead of $51.4 \%$ ). For activity and consumption, real supply shocks have a stronger impact on peripheral aggregates.

As observed, fluctuations in financial indicators related to lending decisions are deeply affected by financial shocks. Contrasting the relative contribution of national, cross-border and common financial shocks, we find that with the noticeable exception of investment (mainly affected by national shocks), variables are mainly affected by common shocks. In contrast, cross-border shocks have only a marginal contribution to the fluctuations of the variables of interest. In most cases, cross-border financial shocks have a higher contribution than cross-border real supply and demand shocks. The main impact of cross-border shocks is observed for financial shocks on financial variables. As an example, peripheral financial shocks account for $7.9 \%$ of the fluctuation of core countries' corporate loan interest rate. As reported, leaving aside activity, core countries variables are more altered by cross-border shocks than peripheral variables .

We evaluate how the transmission of shocks is affected by cross-border loans by contrasting these general findings with the lower part of Table 5. As reported, crossborder banking has a stabilizing effect on financial shocks for activity and consumption (this affects all dimensions of the financial shocks) but increases the contribution of the financial shocks on the fluctuations of the growth rate of investment. Evidence is mixed for other national variables. However has reported, core countries get a higher profit from the integration of the loan market in the Eurozone, as we observe more reduction in the contribution of national financial shocks on national indicators (for 12 variables instead of 9 for peripheral countries). Thus, cross-border lending has a per-se impact on the diffusion of financial shocks as it significantly reduces the contribution of national financial shocks on the fluctuations of national variables.

Finally, contrasting the two models, we find that cross-border lending reduces the contribution of financial shocks to the fluctuations in the central bank interest rate (it explains $71.4 \%$ of the interest rate fluctuations instead of $77.6 \%$ if the loan market is segmented).

\subsection{Understanding the Time Path of the Current Account}

The last rows devoted to the models $\mathcal{M}_{2}$ and $\mathcal{M}_{1}$ in Table 5 present the variance decomposition of current account fluctuations. As reported, it is clearly affected by the integration of the loan market: under loan market segmentation, financial shocks contribute to $57.6 \%$ of current account fluctuations, while they account for $91.8 \%$ with cross-border banking. Remarkably, the contribution of both national and common shocks increase. 
The main contribution to the current account fluctuations comes from peripheral countries financial shocks, that account for $58.9 \%$ of the current account fluctuations over the time period. Thus, despite the increased contribution of common shocks, the current account fluctuations are more closely related to national financial developments: the need for cross-border lending in this fit exercise is not a substitute for common shocks.

We document in panel (c) of Fig. 9 the time path of the current account on a quarter-on-quarter basis by taking the point of view of peripheral countries (that has been characterized by a persistent current account deficit between 2001Q2 and 2007Q4). The solid line depicts the time path of the current account in deviation from the steady state as reported by the data, while bars depict the size of shocks in the corresponding deviation. As observed, the explanatory power of the model is quite high (the darker component in the figure that accounts for other factors not taken into account by the model has only a marginal contribution to the current account deficit) and we can link the time path of the peripheral countries' current account to shocks in a rather reliable way. Over the considered time period, the fluctuations in the current account are quite high (between $-10 \%$ and $+10 \%$ ). As already noticed for the historical variance decomposition, the contribution of real shocks (originating from both the core and the periphery) is marginal. The contribution of core real and nominal developments is almost constant over the sample period and negatively contributes to the current account surplus. In contrast, peripheral real and nominal shocks that initially contributed to the deficit, have a positive (although marginal) contribution to the peripheral current account surplus after the occurrence of the financial crisis in the Eurozone.

Overall, financial shocks are the main drivers of the time path of the current account over the considered period. The deterioration of the current account between 2001Q2 and 2007Q4 is clearly linked to the jointly negative contribution of peripheral, core and common financial shocks, even if the former plays a key role in the reported time path. The transmission of the financial crisis in 2008 on the current account surplus appears as a combination of common and core countries' financial shocks. Leaving aside the first two quarters of 2009, the contribution of peripheral financial shocks remained negative long after the beginning of the financial crisis (at least up to the middle of 2011). They have a clear positive impact on the bilateral current account only since 2011Q3.

In Fig. 9, we also document the time path of cross-border interbank loans on a quarter-on-quarter basis. In panel (a) we report the cross-border loans from core to peripheral countries while in panel (b) we present the time path of cross-border loans from peripheral to core countries. As observed, we get a better fit of the model for the latter phenomenon, especially after 2004Q1. Contrasting the two panels, our model clearly shows that financial innovations are the main drivers of cross border loans, as real and nominal factors contribute only marginally to the reported time path in both 
cases. Common financial factor affecting both regions of the Eurozone have had a positive impact on cross-border lending in both cross-border directions all over the time period. In particular they are the main driver of cross-border loans from peripheral countries. The financial situation of core countries leads to more cross-border loans towards the periphery (they affect positively the reported time path) while it affects negatively cross-border loans from the periphery. In contrast, financial shocks in the periphery contribute positively to cross-border lending from the core and negatively to the core. Putting pieces altogether clearly shows that peripheral countries have benefited form cross border lending over the sample time period: they received more loans than they exported, and this phenomenon has mainly been fuelled by peripheral financial shocks, as already been noted above for the time path of the bilateral current account.

\subsection{Counterfactual Analysis}

We report in Fig. 10 the propagation of the financial crisis of 2009 on the model. We represent it as the sum of all the shocks that affected each economy in 2009Q1. In this figure, plain lines represent the adjustment of the corresponding variable estimated by the model, dotted lines report the IRFs computed with perfect banking integration and dashed lines report the IRFs computed without cross-border lending between the two regions of the Eurozone. We get two main findings from this counterfactual exercise: ( $i$ ) peripheral countries have been much more affected by the crisis than core countries and $(i i)$ the degree of cross-border banking affects the time path of the main national macroeconomic indicators (consumption being the main exception).

First, we find a deeper impact of the financial crisis on interbank loans (reported figures for the IRFs are almost twice the value of corporate loans for each part of the Eurozone). There is a sharp reduction in both corporate and interbank loans in the periphery while, in the core country group, the reduction of interbank loans 'only' diminishes by up to $-10 \%$ (instead of $-40 \%$ for the periphery) and the reduction in corporate loans reaches 'only' $-3 \%$ (instead of $-20 \%$ for the periphery). The persistency of the shock is also much higher on peripheral loans. Cross border banking has deteriorated the evolution of interbank lending in core countries while it has mildly improved the situation of interbank lending in the periphery. In contrast, the degree of cross-border banking estimated by the model between the two group of countries did not have a significant effect on the time path of corporate loans or on the cost of borrowing faced by firms.

Second, the size of the fluctuations in macroeconomic aggregates are in line with the behavior of financial variables, as the fluctuations in activity and investment are much 
more pronounced in the periphery than in the core countries. However, in both parts of the world, the time path of activity mimics that of investment. In the periphery, the financial crisis has clearly led to a sharper and more persistent decrease in investment (reaching a maximum decrease of $-12 \%$ after 8 quarters instead of $-2 \%$ after 5 quarters and going back to equilibrium after 11 periods for the core country group) and activity (reaching a maximum decrease of $-1.5 \%$ after 8 quarters instead of $-0.4 \%$ after 5 quarters and going back to equilibrium after 11 periods for the core country group). The contribution of cross border banking to the observed dynamics of output and investment underlines that cross-border lending has reduced the negative consequences of the financial crisis for core countries, with respect to a segmentation of the loan market, while it has mildly deteriorated the situation of the periphery.

As a final counterfactual exercise, we find that a perfect banking integration of the Eurozone (in dotted lines) would have amplified the fluctuations of all core countries' variables, while dampening that of peripheral countries. This complete integration would have led to a transfer of volatility between the two components of the Eurozone, contributing to a better mutualization of the negative consequences of the financial crisis over the region.

\section{Conclusion}

In this paper, we have developed and estimated a two-country DSGE model with banking activity that accounts for interbank and corporate cross-border loan flows. Using Bayesian econometrics, we have found evidence of the key role of this cross-border channel as an amplifying mechanism in the diffusion of asymmetric shocks. In particular, our model reveals that under banking globalization, most national variables are less sensitive to national financial shocks while investment and current account imbalances are more affected. In a counterfactual analysis, we have analyzed how cross border lending has affected the transmission of the recent financial crisis between the two groups of countries.

Our model contributes to the New Open Economy Macroeconomics literature by finding two new channels of propagation of macroeconomic shocks between countries. Taken altogether, our results underline the critical contribution of corporate and interbank cross-border loans in the Eurozone to account for both the transmission of asymmetric shocks and the effect of monetary policy decisions. In particular, they suggest the importance of cross border loans to assess the impact of the financial accelerator in models of the Eurozone.

Looking forward, our analysis outlines several areas for future research. In particular, 
our model could be used as a framework to assess alternative way of supervising lending decisions (based on the home or host principle) and thus contribute to the current discussion of the best way of implementing macroprudential measures in the European Monetary Union.

\section{References}

An, S., Schorfheide, F., 2007. Bayesian analysis of dsge models. Econometric reviews 26 (2-4), 113-172.

Andrle, M., 2010. A note on identification patterns in dsge models. Tech. rep., European Central Bank Frankfurt.

Angeloni, I., Faia, E., 2013. Capital regulation and monetary policy with fragile banks. Journal of Monetary Economics 60 (3), 311-324.

Bachmann, R., Elstner, S., 2013. Firms optimism and pessimism.

Benigno, P., Woodford, M., 2005. Inflation stabilization and welfare: The case of a distorted steady state. Journal of the European Economic Association 3 (6), 1185-1236.

Bernanke, B., Gertler, M., Gilchrist, S., 1999. The financial accelerator in a quantitative business cycle framework. Handarticle of macroeconomics 1, 1341-1393.

Brooks, S. P., Gelman, A., 1998. General methods for monitoring convergence of iterative simulations. Journal of computational and graphical statistics 7 (4), 434-455.

Casares, M., Poutineau, J., 2011. Short-run and long-run effects of banking in a new keynesian model. The BE Journal of Macroeconomics 11 (1).

Christiano, L., Motto, R., Rostagno, M., 2010. Financial factors in economic fluctuations.

Christiano, L. J., Eichenbaum, M., Evans, C. L., 2005. Nominal rigidities and the dynamic effects of a shock to monetary policy. Journal of political Economy 113 (1), 1-45.

Cúrdia, V., Woodford, M., 2010. Credit spreads and monetary policy. Journal of Money, Credit and Banking 42, 3-35.

De Graeve, F., 2008. The external finance premium and the macroeconomy: Us post-wwii evidence. Journal of Economic Dynamics and Control 32 (11), 3415-3440.

De Grauwe, P., 2010. The scientific foundation of dynamic stochastic general equilibrium (dsge) models. Public choice 144 (3-4), 413-443.

Dedola, L., Karadi, P., Lombardo, G., 2013. Global implications of national unconventional policies. Journal of Monetary Economics 60 (1), 66-85.

Dedola, L., Lombardo, G., 2012. Financial frictions, financial integration and the international propagation of shocks. Economic Policy 27 (70), 319-359.

Dib, A., 2010. Banks, credit market frictions, and business cycles. Tech. rep., Bank of Canada Working Paper. 
Eyquem, A., Poutineau, J.-C., 2010. Markets integration and macroeconomic dispersion in a monetary union. Louvain Economic Review 76 (1), 5-30.

Faia, E., 2007. Finance and international business cycles. Journal of Monetary Economics 54 (4), $1018-1034$.

Faia, E., Iliopulos, E., 2011. Financial openness, financial frictions and optimal monetary policy. Journal of Economic Dynamics and Control 35 (11), 1976-1996.

Gerali, A., Neri, S., Sessa, L., Signoretti, F. M., 2010. Credit and banking in a dsge model of the euro area. Journal of Money, Credit and Banking 42 (s1), 107-141.

Gertler, M., Karadi, P., 2012. A framework for analyzing large scale asset purchases as a monetary policy tool*.

Gilchrist, S., Ortiz, A., Zakrajsek, E., 2009a. Credit risk and the macroeconomy: Evidence from an estimated dsge model. Unpublished manuscript.

Gilchrist, S., Sim, J., Zakrajsek, E., 2009b. Uncertainty, credit spreads, and investment dynamics.

Goodfriend, M., McCallum, B., 2007. Banking and interest rates in monetary policy analysis: A quantitative exploration. Journal of Monetary Economics 54 (5), 1480-1507.

Goodhart, C. A., Sunirand, P., Tsomocos, D. P., 2005. A risk assessment model for banks. Annals of Finance 1 (2), 197-224.

Gray, S., Chailloux, A., McCaughrin, R., 2008. Central bank collateral frameworks: Principles and policies. IMF Working Papers, 1-67.

Guerrieri, L., Iacoviello, M., Minetti, R., 2012. Banks, sovereign debt and the international transmission of business cycles.

Hirakata, N., Sudo, N., Ueda, K., 2009. Chained credit contracts and financial accelerators.

Hirakata, N., Sudo, N., Ueda, K., 2011. Do banking shocks matter for the us economy? Journal of Economic Dynamics and Control 35 (12), 2042-2063.

Iskrev, N., 2010. Local identification in dsge models. Journal of Monetary Economics 57 (2), 189-202.

Kalemli-Ozcan, S., Papaioannou, E., Perri, F., 2013. Global banks and crisis transmission. Journal of International Economics 89 (2), 495-510.

Kolasa, M., 2008. Structural heterogeneity or asymmetric shocks? poland and the euro area through the lens of a two-country dsge model.

Kollmann, R., Enders, Z., Müller, G. J., 2011. Global banking and international business cycles. European Economic Review 55 (3), 407-426.

Lubik, T., Schorfheide, F., 2006. A bayesian look at the new open economy macroeconomics, 313-382.

Obstfeld, M., Rogoff, K., 2001. The six major puzzles in international macroeconomics: is there a common cause?, 339-412. 
Pariès, M. D., Sørensen, C. K., Rodriguez-Palenzuela, D., 2011. Macroeconomic propagation under different regulatory regimes: Evidence from an estimated dsge model for the euro area. International Journal of Central Banking 7 (4), 49-113.

Saltelli, A., Ratto, M., Andres, T., Campolongo, F., Cariboni, J., Gatelli, D., Saisana, M., Tarantola, S., 2008. Global sensitivity analysis: the primer. John Wiley \& Sons.

Schmitt-Grohé, S., Uribe, M., 2003. Closing small open economy models. Journal of international Economics 61 (1), 163-185.

Smets, F., Wouters, R., 2003. An estimated dynamic stochastic general equilibrium model of the euro area. Journal of the European Economic Association 1 (5), 1123-1175.

Smets, F., Wouters, R., 2007. Shocks and frictions in us business cycles: A bayesian dsge approach. American Economic Review 97 (3).

Ueda, K., 2012. Banking globalization and international business cycles: Cross-border chained credit contracts and financial accelerators. Journal of International Economics 86 (1), 1-16.

\section{A Data sources}

Gross domestic product: expenditure approach, millions of national currency, current prices, quarterly levels, seasonally adjusted - sources Eurostat. Private final consumption expenditure: millions of national currency, current prices, quarterly levels, seasonally adjusted - sources Eurostat. Gross fixed capital formation: millions of national currency, current prices, quarterly levels, seasonally adjusted - sources Eurostat. HICP: Overall Index excluding food and energy, Deseasonalized using a multiplicative decomposition - sources ECB. Loans to Non-Financial corporations: Index of Notional Stocks, Total maturity, Euro area (changing composition) counterpart, Deseasonalized using a multiplicative decomposition, monthly data (aggregated to get quarterly data) - sources ECB (internal backcasted series). Loans to MFIs: Index of Notional Stocks, Total maturity, Euro area (changing composition) counterpart, Deseasonalized using a multiplicative decomposition, monthly data (aggregated to get quarterly data) - sources ECB (internal backcasted series). Borrowing cost: monthly (taken in average to get quarterly data), Credit and other institutions (MFI except MMFs and central banks); Loans up to 1 year; BS counterpart sector: Non-Financial corporations (S.11); Outstanding amount - sources ECB. For 1999Q1-2003Q1, we approximated the series by using the interest rate on loans other than revolving loans and overdrafts, New business. Official refinancing operation rates: central bank interest rates, one year maturity, quarterly data - sources Eurostat. Wages: Labour cost index, nominal value - quarterly data (NACE Rev. 2), Seasonally adjusted and 
adjusted data by working days, Business economy, Wages and salaries (total) - sources Eurostat.

\section{B Pareto distribution of financial contracts}

We assume that each entrepreneur $e \in[0,1]$ conducts a mass $\omega \in\left[\omega_{\min },+\infty[\right.$ of heterogeneous investment projects, they are risky so that some of the projects will have negative profits. To model individual riskiness, we assume that the aggregate return of investment projects $R_{i, t}^{k}$ is multiplied by a random value $\omega$ (drawn from a Pareto distribution), so that the net return of its individual project is, $\omega R_{i, t}^{k}$. Since he must repay to the bank $L_{i, t+1}^{\mathcal{H}}(e)$ given a borrowing rate $P_{i, t}^{L}(e)$, the net profit of the project $\omega$ is $\omega R_{i, t}^{k} Q_{i, t-1} K_{i, t}(e, \omega)-P_{i, t-1}^{L}(e) L_{i, t}^{\mathcal{H}}(e, \omega)$. To separate profitable investment project from non-profitable ones, there exists a critical value (a cutoff point) defined as $\omega_{i, t}^{C}(e)$ such that the project just breaks even. Thereby the threshold is computed by,

$$
\omega_{i, t}^{C}(e) R_{i, t}^{k} Q_{i, t-1} K_{i, t}\left(e, \omega_{i, t}^{C}\right)=P_{i, t-1}^{L}(e) L_{i, t}^{\mathcal{H}}\left(e, \omega_{i, t}^{C}\right)
$$

Recall that $\omega \sim \mathcal{P}\left(\kappa, \omega_{\min }\right)$ where $\omega \in\left[\omega_{\min } ;+\infty[, \kappa>1\right.$ is the shape parameter and $\omega_{\min }>0$ is the minimum bound of $\omega$. The conditional expectation of $\omega$ when entrepreneur's project is gainful is, $\eta \bar{\omega}=\int_{\omega^{C}}^{\infty} \omega f(\omega) d \omega$, while the conditional expectation of $\omega$ when entrepreneur's project is insolvent is, $(1-\eta) \underline{\omega}=\int_{\omega_{\min }}^{\omega^{C}} \omega f(\omega) \mathrm{d} \omega$. The share of profitable projects is computed as, $\eta=\operatorname{Pr}\left[\omega \geq \omega^{C}\right]=\int_{\omega^{C}}^{\infty} f(\omega) \mathrm{d} \omega=$ $\left(\omega_{\min } / \omega^{C}\right)^{\kappa}$. The conditional expectation is computed via, $\bar{\omega}=E\left[\omega \mid \omega \geq \omega^{C}\right]=$ $\int_{\omega^{C}}^{\infty} \omega f(\omega) \mathrm{d} \omega / \int_{\omega^{C}}^{\infty} f(\omega) \mathrm{d} \omega=\frac{\kappa}{\kappa-1} \omega^{C}$. Since $E[\omega]=\eta E\left[\omega \mid \omega \geq \omega^{C}\right]+(1-\eta) E\left[\omega \mid \omega<\omega^{C}\right]=$ 1 , then $\underline{\omega}=(1-\eta \bar{\omega}) /(1-\eta)$. 


\begin{tabular}{lccccccc}
\hline \hline & \multicolumn{4}{c}{ Prior distributions } & \multicolumn{3}{c}{ Posterior distribution [5\%:95\%] } \\
& & Shape & Mean & Std. & CORE & PERIPHERY & EURO \\
\hline Productivity std & $\sigma_{i}^{A}$ & $\mathcal{I} \mathcal{G}$ & 0.10 & 2 & $0.88[0.67: 1.08]$ & $0.76[0.58: 0.92]$ & - \\
Gov. spending std & $\sigma_{i}^{G}$ & $\mathcal{I} \mathcal{G}$ & 0.10 & 2 & $1.64[1.37: 1.90]$ & $1.66[1.39: 1.93]$ & - \\
Preferences std & $\sigma_{i}^{\beta}$ & $\mathcal{I} \mathcal{G}$ & 0.10 & 2 & $1.59[1.08: 2.07]$ & $2.12[1.29: 2.90]$ & - \\
Net Wealth std & $\sigma_{i}^{N}$ & $\mathcal{I} \mathcal{G}$ & 0.10 & 2 & $0.14[0.08: 0.21]$ & $0.15[0.06: 0.23]$ & $0.14[0.08: 0.19]$ \\
External Finance std & $\sigma_{i}^{Q}$ & $\mathcal{I} \mathcal{G}$ & 0.10 & 2 & $0.46[0.03: 0.78]$ & $0.42[0.03: 0.79]$ & $0.82[0.64: 1.01]$ \\
Bank cost-push std & $\sigma_{i}^{L}$ & $\mathcal{I} \mathcal{G}$ & 0.10 & 2 & $0.27[0.03: 0.48]$ & $0.22[0.02: 0.47]$ & $0.68[0.45: 0.90]$ \\
Bank Liab. std & $\sigma_{i}^{B}$ & $\mathcal{I} \mathcal{G}$ & 0.10 & 2 & $2.28[1.77: 2.78]$ & $2.43[1.80: 3.03]$ & $0.08[0.02: 0.16]$ \\
Wage cost-push std & $\sigma_{i}^{W}$ & $\mathcal{I} \mathcal{G}$ & 0.10 & 2 & $0.92[0.56: 1.24]$ & $1.65[0.86: 2.47]$ & - \\
Monetary policy std & $\sigma^{R}$ & $\mathcal{I} \mathcal{G}$ & 0.10 & 2 & - & - & $0.09[0.07: 0.11]$ \\
\hline Productivity AR & $\rho_{i}^{A}$ & $\mathcal{B}$ & 0.85 & 0.10 & $0.99[0.98: 1.00]$ & $0.99[0.98: 1.00]$ & - \\
Gov.spending AR & $\rho_{i}^{G}$ & $\mathcal{B}$ & 0.85 & 0.10 & $0.93[0.88: 0.98]$ & $0.91[0.83: 0.99]$ & - \\
Preferences AR & $\rho_{i}^{\beta}$ & $\mathcal{B}$ & 0.85 & 0.10 & $0.81[0.72: 0.91]$ & $0.54[0.38: 0.70]$ & - \\
Net Wealth AR & $\rho_{i}^{N}$ & $\mathcal{B}$ & 0.85 & 0.10 & $0.96[0.92: 0.99]$ & $0.96[0.93: 1.00]$ & - \\
Riskiness AR & $\rho_{i}^{Q}$ & $\mathcal{B}$ & 0.85 & 0.10 & $0.47[0.35: 0.59]$ & $0.59[0.47: 0.71]$ & - \\
Bank cost-push AR & $\sigma_{i}^{L}$ & $\mathcal{B}$ & 0.85 & 0.10 & $0.99[0.98: 1.00]$ & $0.90[0.84: 0.96]$ & - \\
Bank Liab. AR & $\rho_{i}^{B}$ & $\mathcal{B}$ & 0.85 & 0.10 & $0.90[0.83: 0.97]$ & $0.93[0.88: 0.99]$ & - \\
Wage cost-push AR & $\sigma_{i}^{W}$ & $\mathcal{B}$ & 0.85 & 0.10 & $0.99[0.99: 1.00]$ & $0.99[0.99: 1.00]$ & - \\
Wage MA term & $u_{i}^{W}$ & $\mathcal{B}$ & 0.85 & 0.10 & $0.51[0.26: 0.77]$ & $0.28[0.07: 0.49]$ & - \\
Taylor AR & $\rho_{i}^{R}$ & $\mathcal{B}$ & 0.85 & 0.10 & - & & - \\
Productivity-Spending & $\rho_{i}^{a g}$ & $\mathcal{B}$ & 0.85 & 0.10 & $0.84[0.69: 0.99]$ & $0.83[0.69: 0.99]$ & - \\
\hline \hline
\end{tabular}

Table 3: Prior and Posterior distributions of shock processes 


\begin{tabular}{lccccccc}
\hline \hline & \multicolumn{4}{c}{ Prior distributions } & \multicolumn{3}{c}{ Posterior distribution [5\%:95\%] } \\
& & Shape & Mean & Std. & CORE & PERIPHERY & EURO \\
\hline Cons. aversion & $\sigma_{i}^{c}$ & $\mathcal{N}$ & 2 & 0.30 & $2.00[1.56: 2.45]$ & $2.04[1.57: 2.49]$ & - \\
Cons. inertia & $h_{i}^{c}$ & $\mathcal{B}$ & 0.7 & 0.10 & $0.32[0.21: 0.42]$ & $0.57[0.46: 0.68]$ & - \\
Labour disutility & $\sigma_{i}^{L}$ & $\mathcal{G}$ & 1 & 0.30 & $0.59[0.30: 0.88]$ & $0.66[0.36: 0.96]$ & - \\
Calvo prices & $\theta_{i}^{p}$ & $\mathcal{B}$ & 0.5 & 0.10 & $0.56[0.47: 0.65]$ & $0.56[0.47: 0.65]$ & - \\
Indexation prices & $\xi_{i}^{p}$ & $\mathcal{B}$ & 0.5 & 0.2 & $0.07[0.01: 0.14]$ & $0.08[0.01: 0.16]$ & - \\
Calvo wages & $\theta_{i}^{w}$ & $\mathcal{B}$ & 0.5 & 0.10 & $0.67[0.56: 0.78]$ & $0.6[0.49: 0.72]$ & - \\
Indexation wages & $\xi_{i}^{w}$ & $\mathcal{B}$ & 0.5 & 0.10 & $0.46[0.16: 0.76]$ & $0.36[0.07: 0.64]$ & - \\
Calvo banks rates & $\theta_{i}^{L}$ & $\mathcal{B}$ & 0.5 & 0.10 & $0.29[0.20: 0.38]$ & $0.31[0.18: 0.43]$ & - \\
Indexation bank rates & $\xi_{i}^{L}$ & $\mathcal{B}$ & 0.5 & 0.15 & $0.12[0.01: 0.22]$ & $0.21[0.05: 0.37]$ & - \\
Investment adj. costs & $\mathcal{X}_{i}^{I}$ & $\mathcal{N}$ & 4 & 1.5 & $0.63[0.38: 0.86]$ & $1.87[1.16: 2.58]$ & - \\
Monitoring cost & $\chi_{i}^{I B}$ & $\mathcal{N}$ & 0.5 & 0.2 & $0.48[0.28: 0.68]$ & $0.23[0.00: 0.48]$ & - \\
Capital utilization & $\psi_{i}$ & $\mathcal{B}$ & 0.5 & 0.15 & $0.66[0.47: 0.85]$ & $0.68[0.51: 0.86]$ & - \\
EF. Premia Elasticity & $\varkappa_{i}$ & $\mathcal{B}$ & 0.1 & 0.05 & $0.05[0.01: 0.09]$ & $0.08[0.02: 0.15]$ & - \\
Firms loans habits & $h_{i}^{L}$ & $\mathcal{B}$ & 0.5 & 0.2 & $0.96[0.93: 0.99]$ & $0.95[0.92: 0.98]$ & - \\
Interbank loans habit & $h_{i}^{B}$ & $\mathcal{B}$ & 0.5 & 0.2 & $0.20[0.05: 0.34]$ & $0.21[0.07: 0.35]$ & - \\
Illiquid bank share & $\lambda$ & $\mathcal{B}$ & 0.5 & 0.08 & - & - & $0.25[0.20: 0.29]$ \\
MPR smoothing & $\rho$ & $\mathcal{B}$ & 0.85 & 0.10 & - & - & $0.84[0.81: 0.88]$ \\
MPR Inflation & $\phi^{\pi}$ & $\mathcal{N}$ & 2 & 0.15 & - & - & $1.85[1.60: 2.10]$ \\
MPR GDP & $\phi^{\Delta y}$ & $\mathcal{N}$ & 0.12 & 0.05 & - & - & $0.15[0.08: 0.23]$ \\
Cons. openness & $\alpha^{C}$ & $\mathcal{B}$ & 0.10 & 0.04 & - & - & $0.17[0.11: 0.23]$ \\
Investment openness & $\alpha^{I}$ & $\mathcal{B}$ & 0.08 & 0.04 & - & - & $0.06[0.01: 0.10]$ \\
Corporate openness & $\alpha^{L}$ & $\mathcal{B}$ & 0.08 & 0.04 & - & - & $0.09[0.03: 0.15]$ \\
Interbank openness & $\alpha^{I B}$ & $\mathcal{B}$ & 0.2 & 0.07 & - & - & $0.11[0.05: 0.17]$ \\
Subst. final good & $\mu$ & $\mathcal{G}$ & 1 & 0.75 & - & - & $2.43[3.09: 5.75]$ \\
Subst. corporate loan & $\nu$ & $\mathcal{G}$ & 1 & 0.75 & - & - & - \\
Subst. interbank loan & $\xi$ & $\mathcal{G}$ & 1 & 0.75 & - & $-0.03: 4.07]$ \\
\hline \hline
\end{tabular}

Table 4: Prior and Posterior distributions of structural parameters 

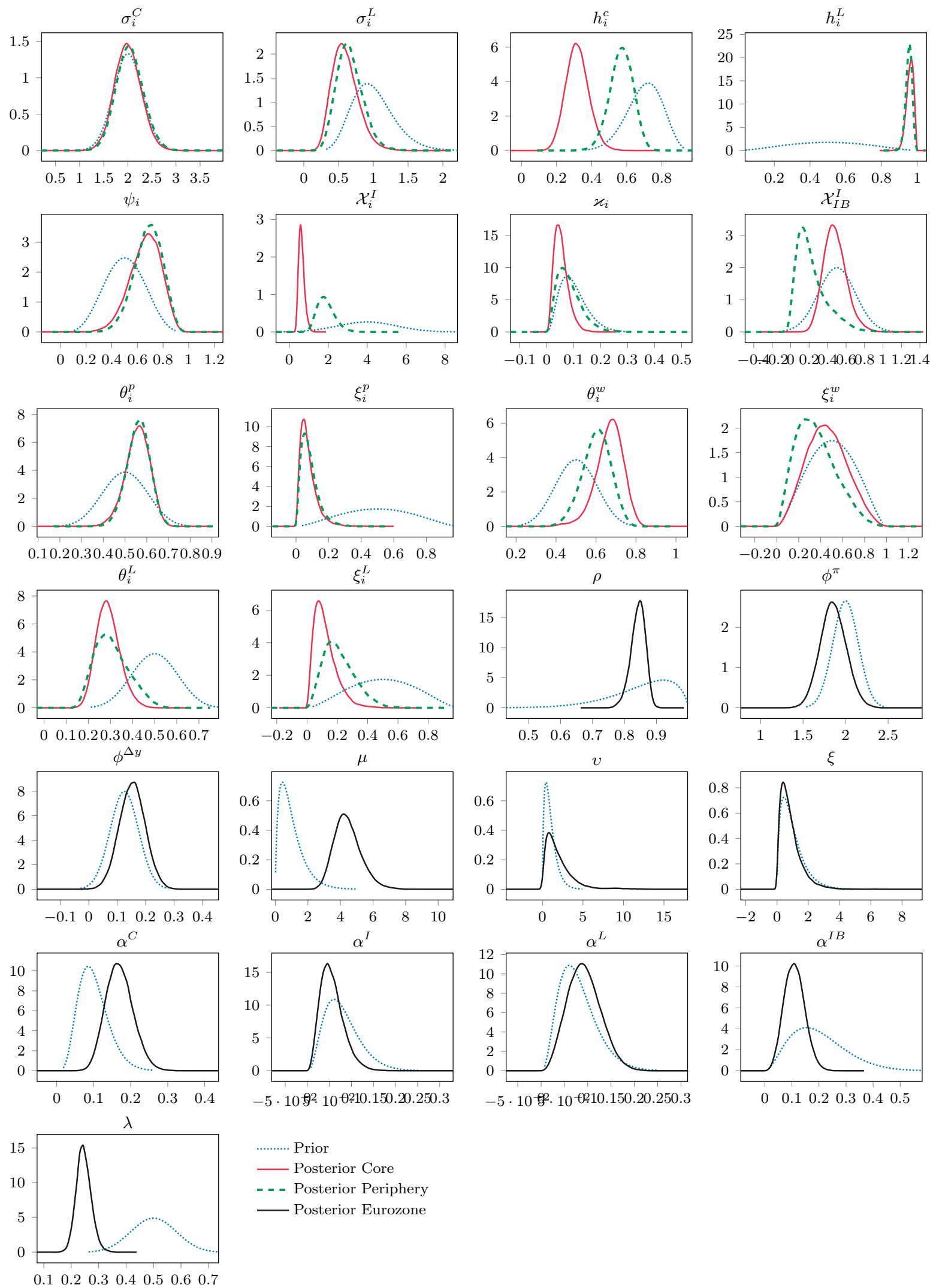

Figure 5: The priors and posteriors distributions of the model parameters with crossborder banking flows. 
CORE COUNTRIES

Production $Y_{h} \quad$ Consumption $C_{h}$

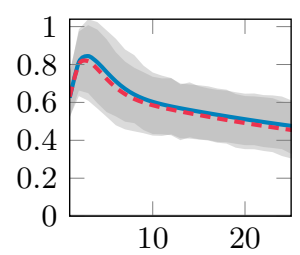

Investment $I_{h}$
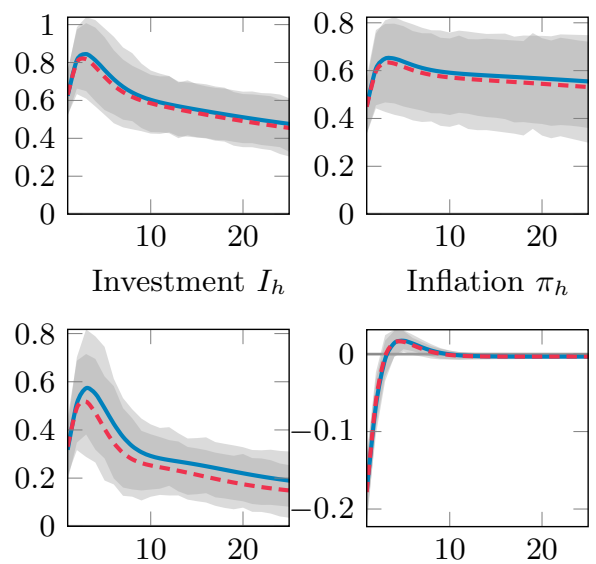

Inflation $\pi_{h}$

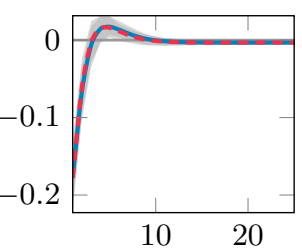

Credit to Firms $L_{h}^{s}$ Borrowing Cost $P_{h}^{L}$
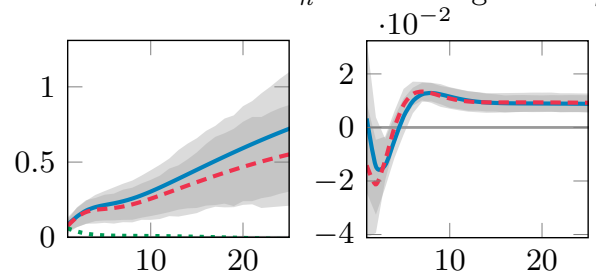

Interbank funds $L_{h}^{I B}$ Interbank Rate $P_{h}^{I B}$
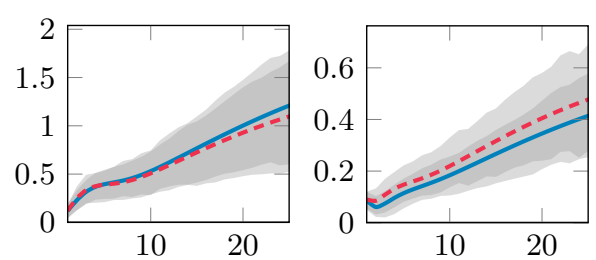

PERIPHERAL COUNTRIES

Production $Y_{f} \quad$ Consumption $C_{f}$

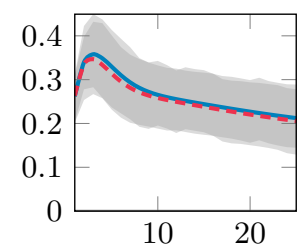

ECB Rate $R$
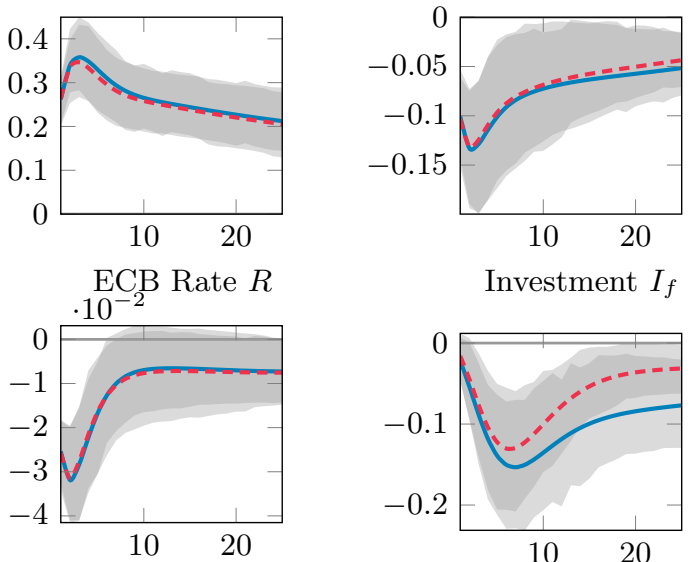

Investment $I_{f}$
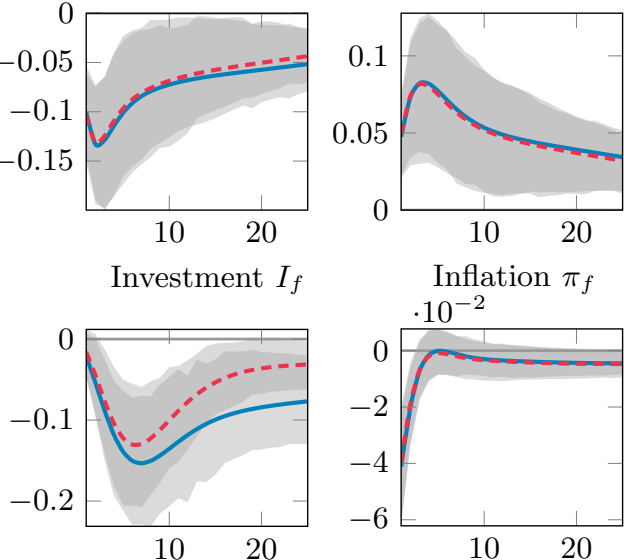

Inflation $\pi_{f}$

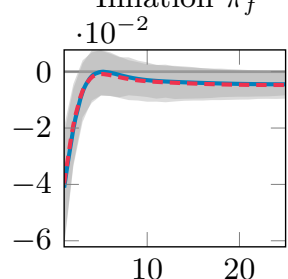

Credit to Firms $L_{f}^{s} \quad$ Borrowing Cost $P_{f}^{L}$
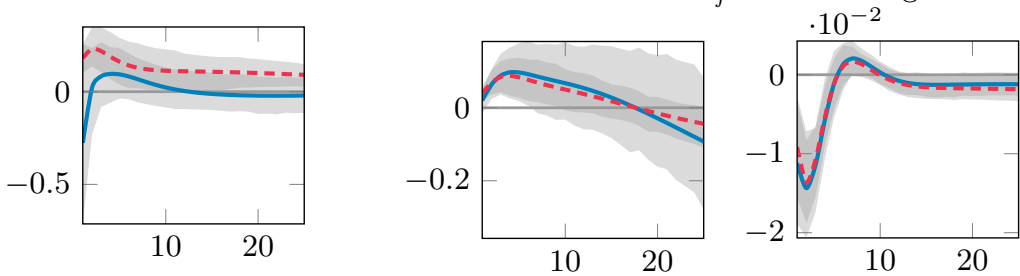

Interbank funds $L_{f}^{I B}$ Interbank Rate $P_{f}^{I B}$

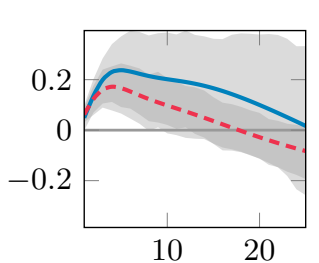

- With cross-border banking $\alpha^{L}=0.09$ and $\alpha^{I B}=0.11 \quad$ - - - $\quad$ Banking autarky $\alpha^{L}=\alpha^{I B}=0$

Figure 6: Bayesian system response to an estimated positive productivity shock in core countries under banking globalization $\left(\alpha^{L}=9 \%, \alpha^{I B}=11 \%\right)$ and autarky $\left(\alpha^{L}=\right.$ $\left.\alpha^{I B}=0 \%\right)$ 
CORE COUNTRIES

Production $Y_{h}$

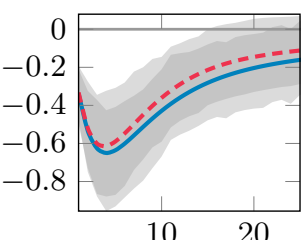

Investment $I_{h}$

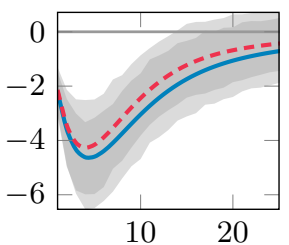

Credit to Firms $L_{h}^{s}$
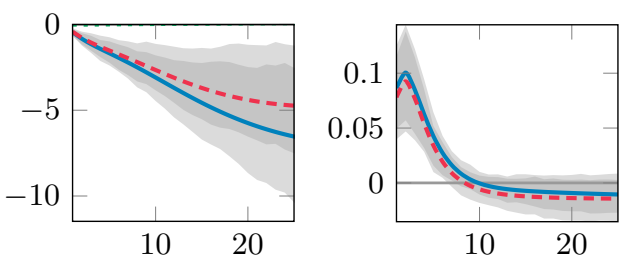

Interbank funds $L_{h}^{I B} \quad$ Interbank Rate $P_{h}^{I B}$
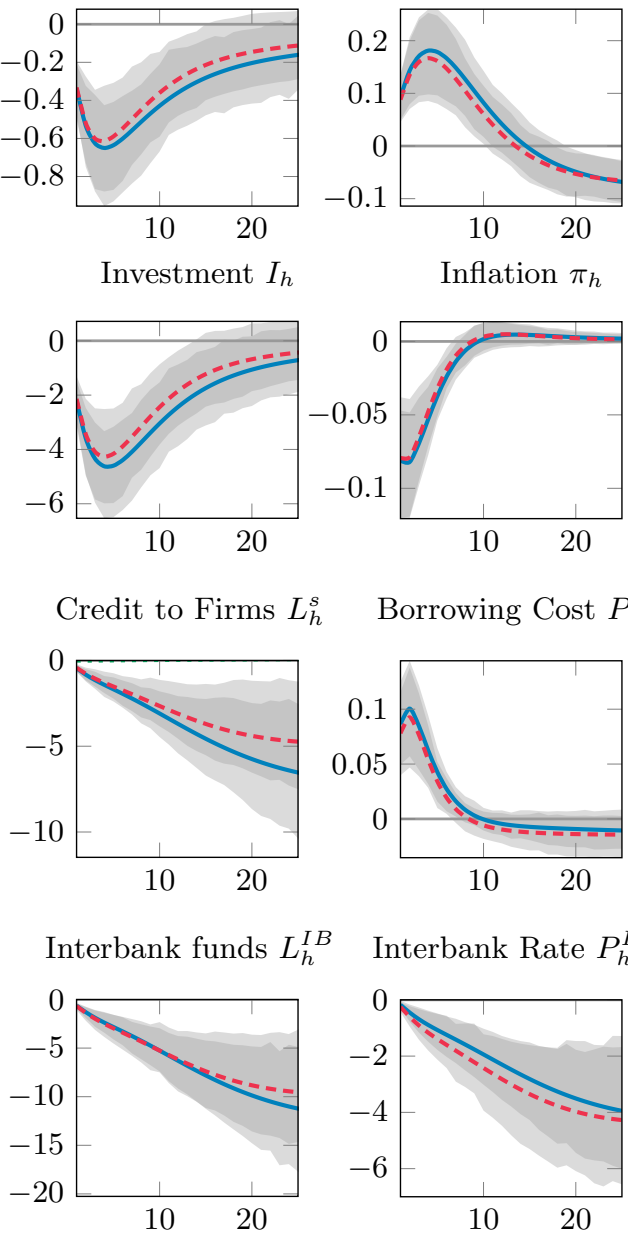

Inflation $\pi_{h}$

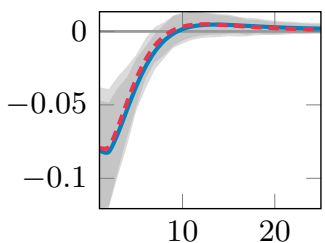

Borrowing Cost $P_{h}^{L}$
EURO AREA

Production $Y_{h}+Y_{f}$

Current Account $C A_{h}$

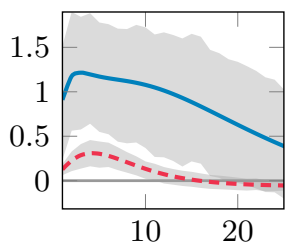

Term of Trade $T o T_{h}$

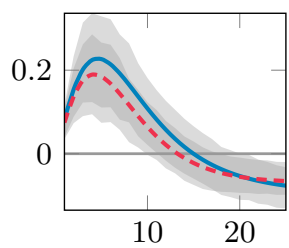

PERIPHERAL COUNTRIES

Production $Y_{f}$

Consumption $C_{f}$
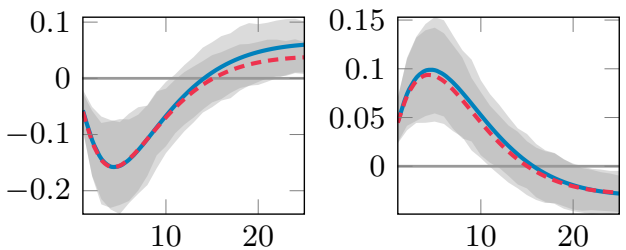

Investment $I_{f}$
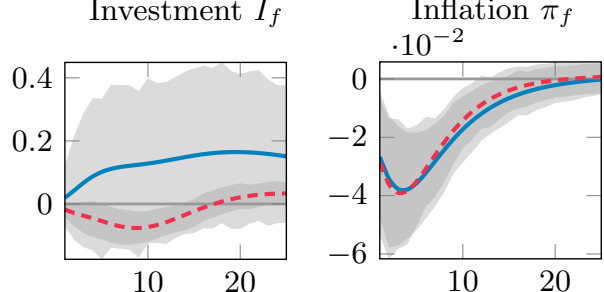

Credit to Firms $L_{f}^{s} \quad$ Borrowing Cost $P_{f}^{L}$
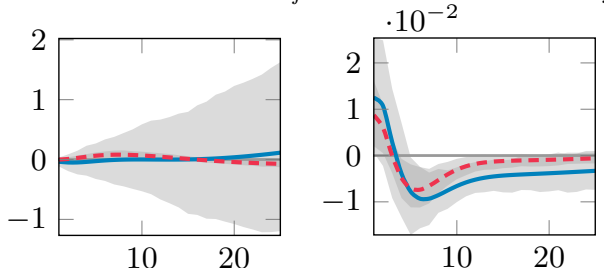

Interbank funds $L_{f}^{I B} \quad$ Interbank Rate $P_{f}^{I B}$
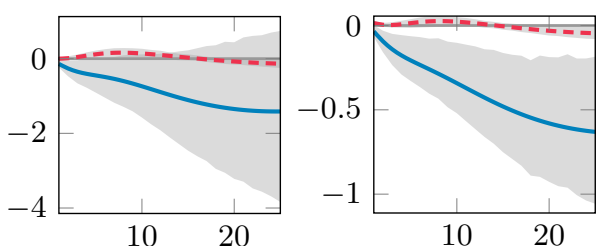

With cross-border banking $\alpha^{L}=0.09$ and $\alpha^{I B}=0.11$

- - - $\quad$ Banking autarky $\alpha^{L}=\alpha^{I B}=0$

Figure 7: Bayesian system response to an estimated negative net wealth shock in core countries under banking globalization $\left(\alpha^{L}=9 \%, \alpha^{I B}=11 \%\right)$ and autarky $\left(\alpha^{L}=\right.$ $\left.\alpha^{I B}=0 \%\right)$ 
CORE COUNTRIES

Production $Y_{h}$

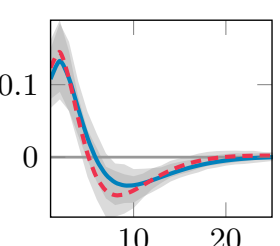

Investment $I_{h}$
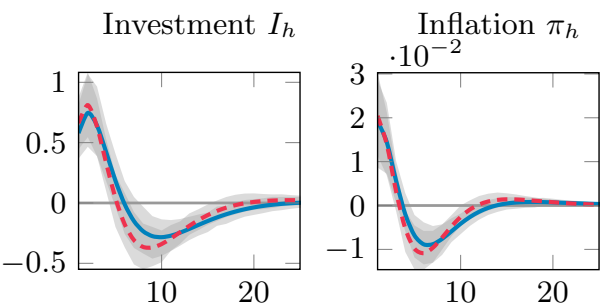

Credit to Firms $L_{h}^{s} \quad$ Borrowing Cost $P_{h}^{L}$

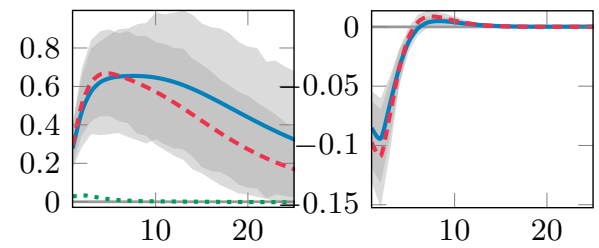

Interbank funds $L_{h}^{I B}$ Interbank Rate $P_{h}^{I B}$
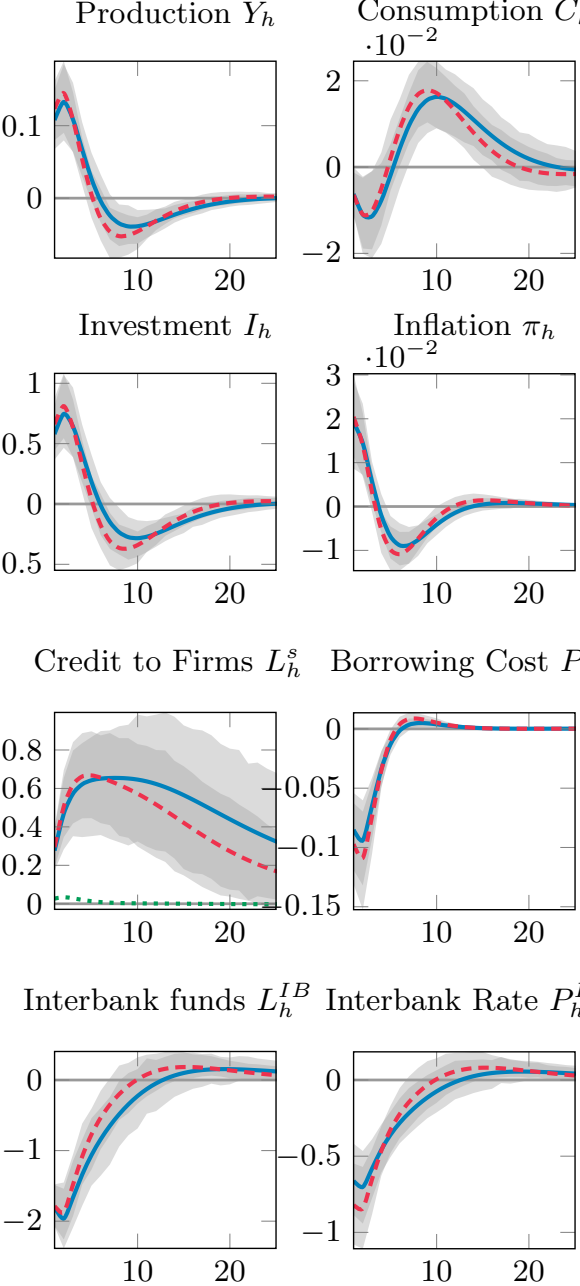

EURO AREA

Production $Y_{h}+Y_{f}$
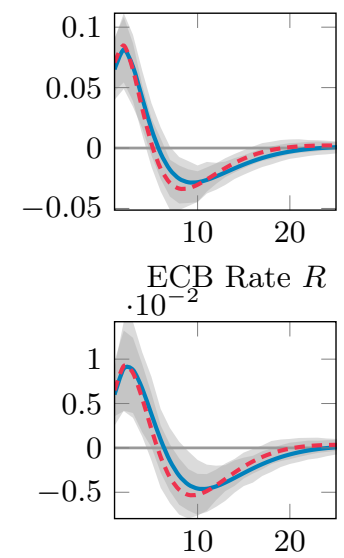

Current Account $C A_{h}$

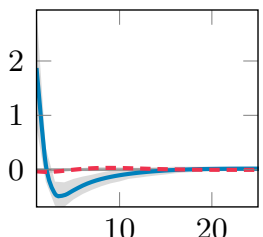

Term of Trade $T o T_{h}$

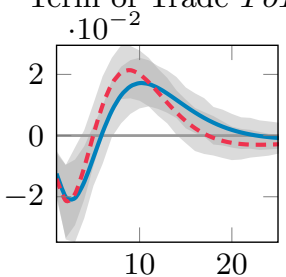

PERIPHERAL COUNTRIES

Production $Y_{f}$
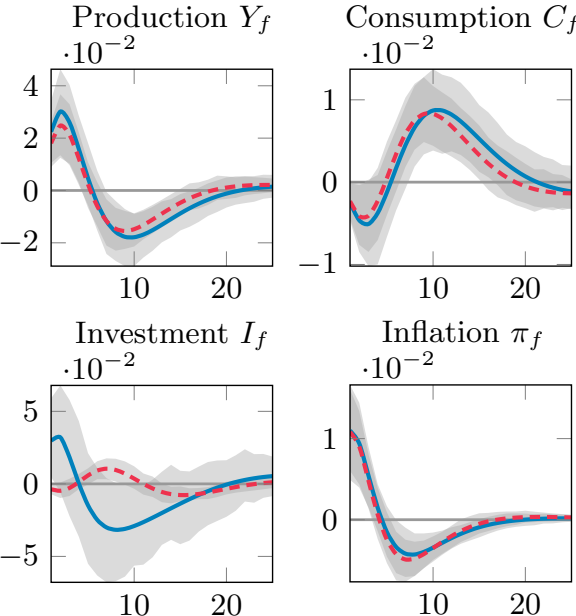

Inflation $\pi_{f}$

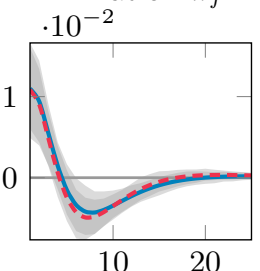

Credit to Firms $L_{f}^{s} \quad$ Borrowing Cost $P_{f}^{L}$
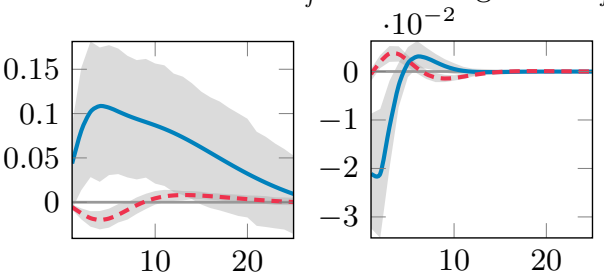

Interbank funds $L_{f}^{I B}$ Interbank Rate $P_{f}^{I B}$

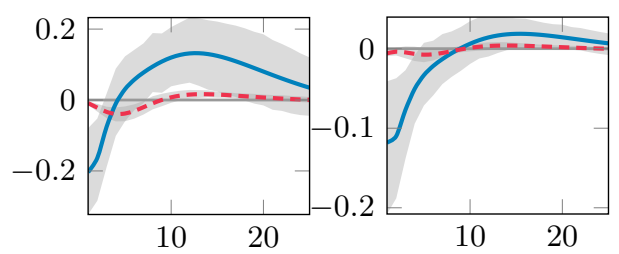

With cross-border banking $\alpha^{L}=0.09$ and $\alpha^{I B}=0.11$

- - - $\quad$ Banking autarky $\alpha^{L}=\alpha^{I B}=0$

Figure 8: Bayesian system response to an estimated positive liabilities shock in the balance sheet of core countries banks under banking globalization $\left(\alpha^{L}=9 \%, \alpha^{I B}=\right.$ $11 \%)$ and autarky $\left(\alpha^{L}=\alpha^{I B}=0 \%\right)$ 


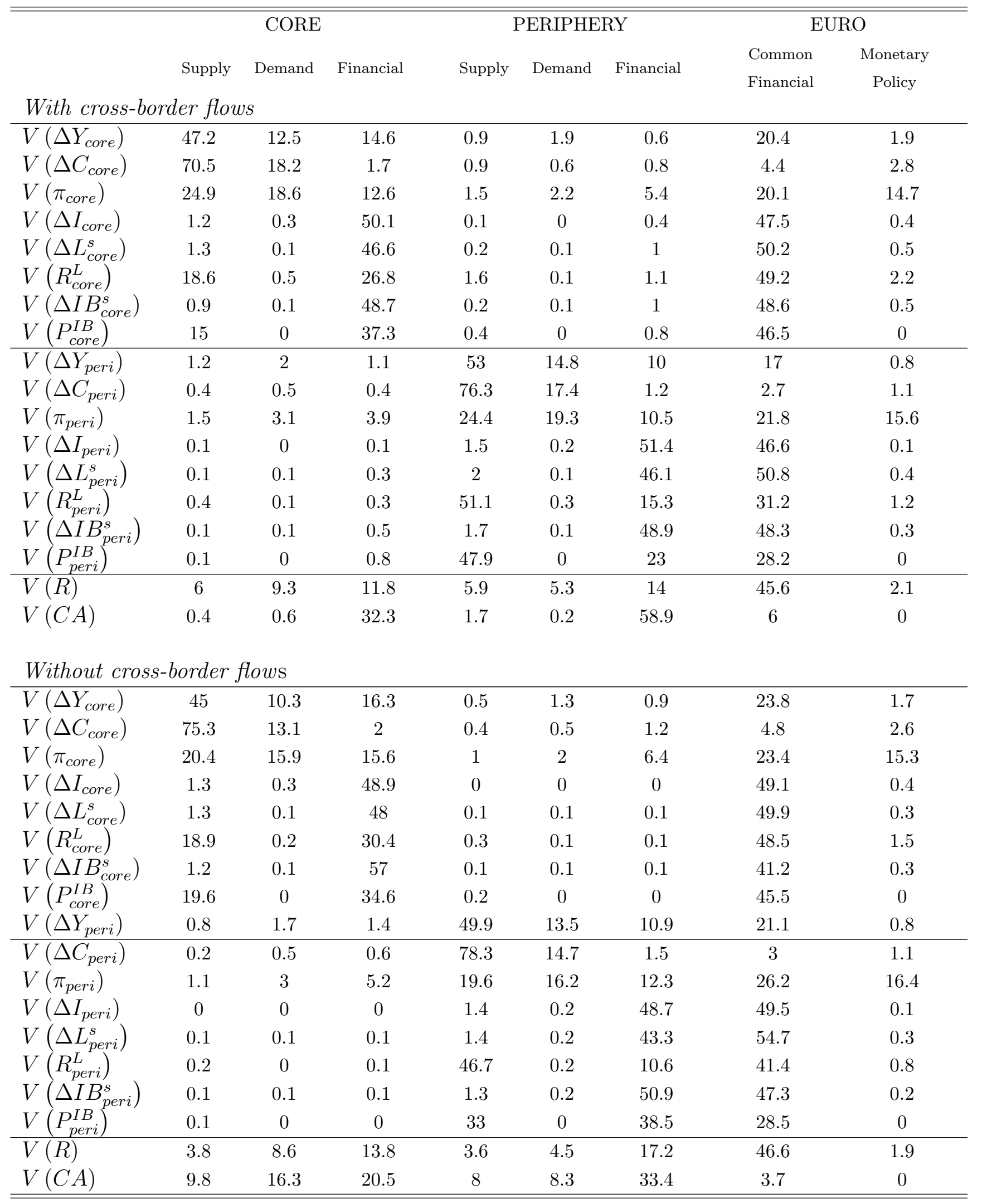

Table 5: The unconditional variance decomposition is the share of variance accounted for by each shock of the model estimated with and without cross-border flows.

Note: The supply group gathers productivity $\left(\eta_{i, t}^{A}\right)$ and wage cost-push $\left(\eta_{i, t}^{W}\right)$ shocks, demand group gathers preferences $\left(\eta_{i, t}^{\beta}\right)$ and spending $\left(\eta_{i, t}^{G}\right)$, financial group gathers collateral $\left(\eta_{i, t}^{N}\right)$ riskiness $\left(\eta_{i, t}^{Q}\right)$ rate cost-push $\left(\eta_{i, t}^{L}\right)$ and banks liabilities $\left(\eta_{i, t}^{B}\right)$ and common financial group gathers collateral $\left(\eta_{t}^{N}\right)$ riskiness $\left(\eta_{t}^{Q}\right)$ rate cost-push $\left(\eta_{t}^{L}\right)$, banks liabilities $\left(\eta_{t}^{B}\right)$ and monetary policy $\left(\eta_{t}^{R}\right)$. 
(a) Cross-border loans from Core to Peripheral countries

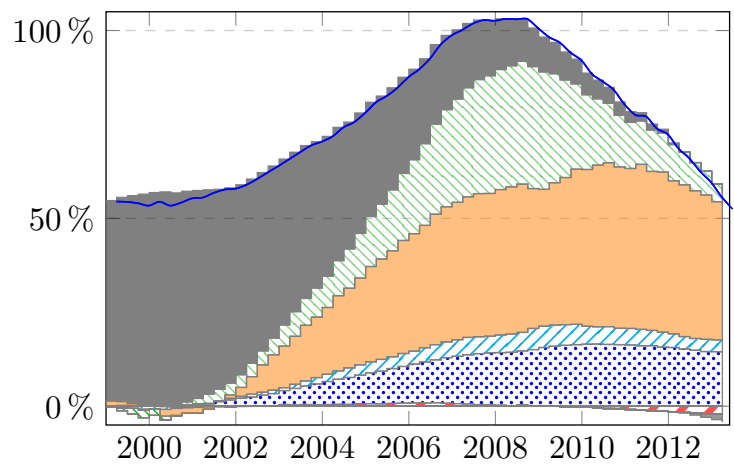

(b) Cross-border loans from Peripheral to Core countries

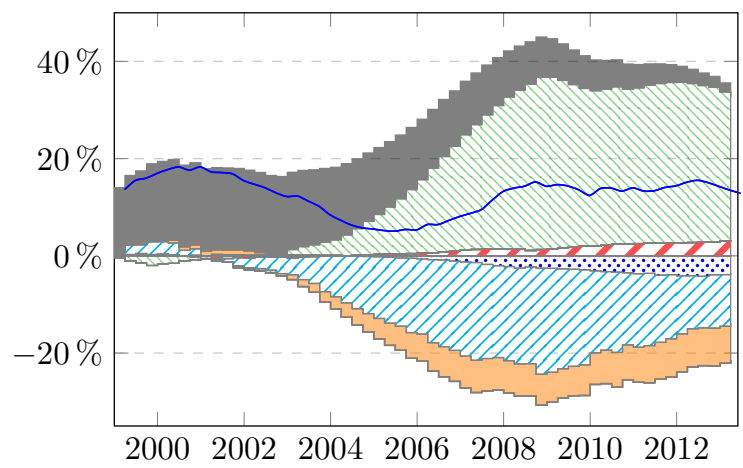

(c) Peripheral Current Account $C A_{f}=-C A_{h}$

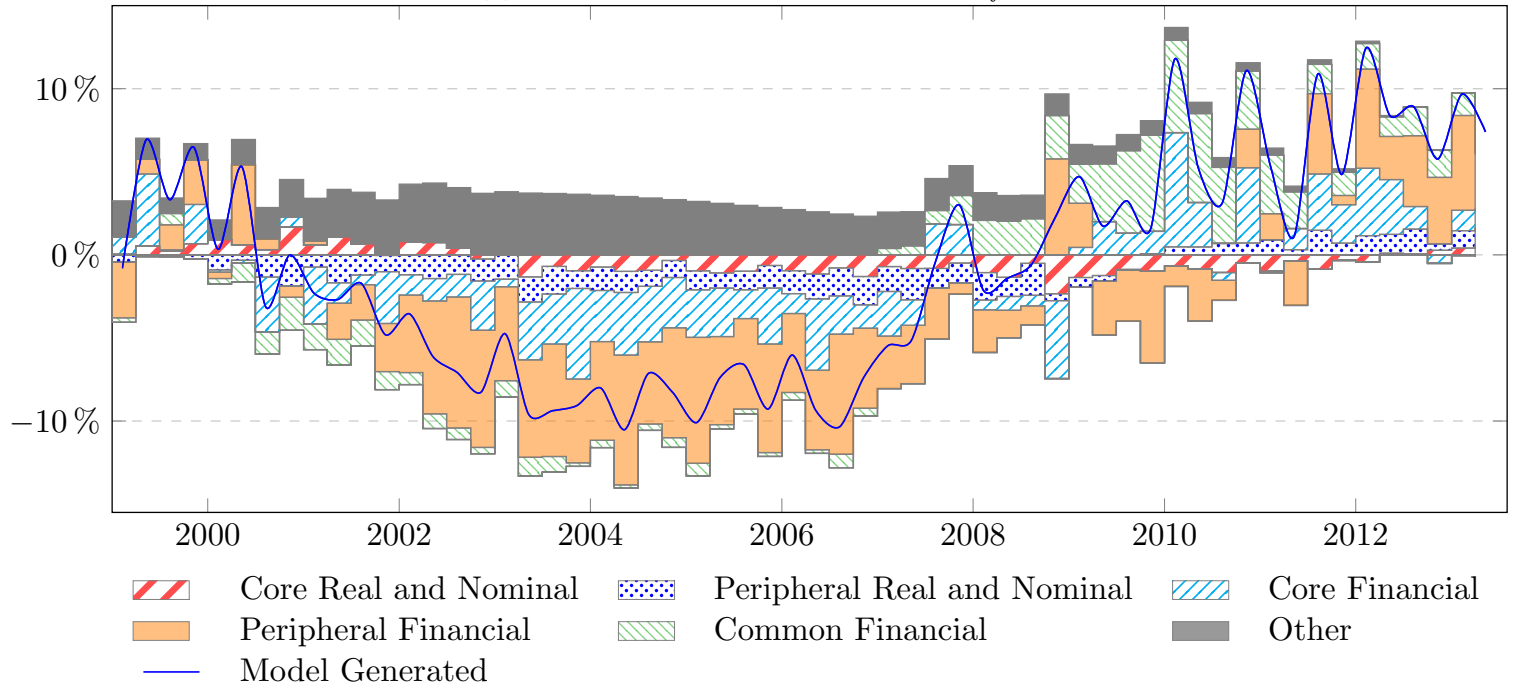

Figure 9: The peripheral current account (quarter-on-quarter $\%$ change generated by the model with cross-border flows).

Note: The solid blue line depicts the quarterly growth rate in real GDP and Investment (per capita), expressed in percentage point deviations from the model's steady state. The colored bars depict the estimated contributions of the various groups of shocks (Real and Nominal: productivity, wage cost-push, spending, preferences asymmetric shocks; Financial: external finance premium, credit cost push, net worth and liabilities asymmetric shocks; Common Financial: external finance premium, credit cost push, net worth, bank liabilities and monetary policy common shocks. 


\section{CORE COUNTRIES}

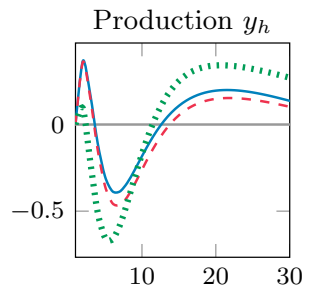

Investment $i_{h}$

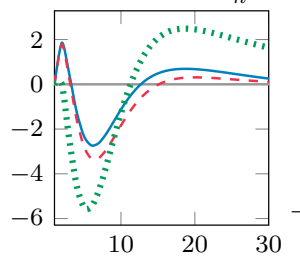

Firms Loan Cost $p_{h}^{l}$

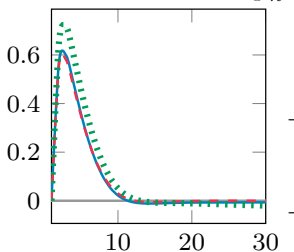

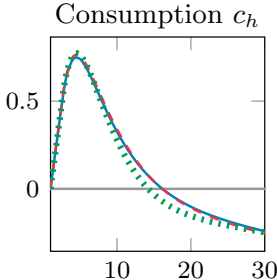

Firms Loans Supply $l_{h}^{s}$

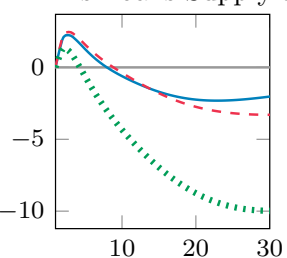

Interbank Loans $i b_{h}^{s}$

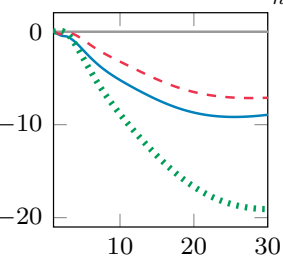

PERIPHERAL COUNTRIES
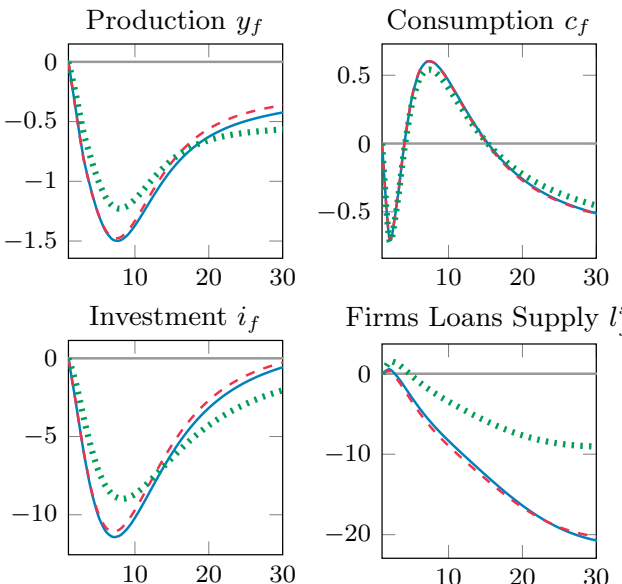

Firms Loans Supply $l_{f}^{s}$

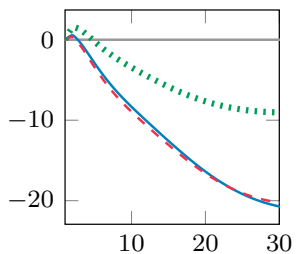

Firms Loan Cost $p_{f}^{l}$

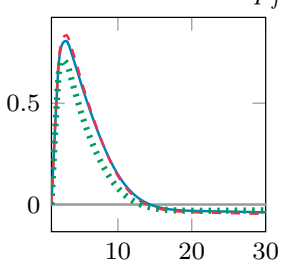

Interbank Loans $i b_{f}^{s}$

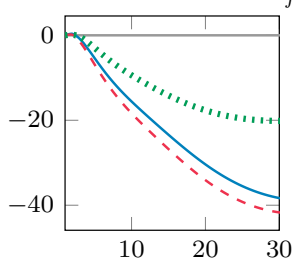

- - Banking Autarky

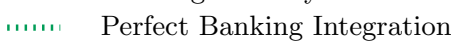

Figure 10: The system response during the financial crisis (2009Q1) under different levels of financial openness 